SISTEMA DE ENTERRAMIENTOS EN TULUM

\author{
VARGAS P. ERNESTO \\ SANTILlán S. Patricia \\ I.I.A. UNAM.
}

\begin{abstract}
Muertos, los amortajaban, llenándoles la boca de maíz molido, que es su comida y bebida que llaman koyem, y con ello algunas piedras de las que tienen por moneda, para que en la otra vida no les faltase de comer. Enterrábanlos dentro de sus casas o a las espaldas de ellas, echándoles en la sepultura algunos de sus ídolos; y si era sacerdote, algunos de sus libros; y si hechicero, sus piedras de hechizo y petrechos (Landa 1978:59).
\end{abstract}

\title{
Introducción.
}

A pesar de la enorme riqueza arqueológica del país, el estudio de los enterramientos humanos en el área maya puede considerarse relativamente limitado debido principalmente a agentes ambientales como son: la temperatura, la humedad y la composición química del terreno (Comas 1966). Panorama que en los últimos años ha cambiado considerablemente, pues las exploraciones se han multiplicado y se tiene en la actualidad colecciones oseas de gran importancia, algunas en proceso de estudio y otras ya publicadas.

En los trabajos realizados por el proyecto arqueologico de Tulum se exploraron varias tumbas y enterramientos humanos, y así 
los antropologos físicos tienen a su disposición un material óseo importante para sus estudios, que en parte resuelve la incognita del sistema de enterramientos del lugar.

La información arqueologica existente sobre las costumbres funerarias de los antiguos pobladores de Tulum, demuestra que éstas eran casi desconocidas. De hecho, los únicos datos con los que se contaba eran los reportados por Lothrop (1924) y los recopilados por Ruz L. (1968) en su trabajo sobre Costumbres funerarias de los antiguos mayas. El estudio que presentamos sobre el tema puede ser de gran interes, pues cambia algunas de las concepciones que se tenían acerca del sitio.

La forma de disponer del cadáver en el área maya varfa de un lugar a otro; en Tulum, además de los enterramientos individuales se exploraron varios osarios de los que nos ocuparemos posteriormente.

Romano (1974) dice que en las poblaciones prehispánicas los entierros en osarios son una costumbre común y extendida y que en la sociedad maya tal práctica era frecuente. La variación debio adecuarse tanto a las condiciones del lugar, como a la evolución en el desarrollo y complejidad social. Las diferencias son notables en los distintos periodos cronológicos, así como en una misma region, e incluso se aprecian hasta en el interior de cada sitio.

En Tulum se exploraron 4 tumbas, 14 entierros, 2 fosas; todos los restos óseos fueron encontrados en construcciones del período Posclásico (fig. 1).

En general los enterramientos que se exploraron provienen de estructuras - tipo palacio-, de plataformas sin paredes de mampostería ni detalles arquitectónicos relevantes; otros, de terrazas localizados en el material de relleno.

Villa Rojas (1985:100) nos dice que todavía es costumbre entre los nativos de Quintana Roo enterrar a sus muertos en tomo a las casas o en el interior de las mismas; en esta zona no se usa ataúd, sino una simple tabla.

En cuanto a la posición de los enterramientos se pudo apreciar que la costumbre más notoria fue la de formar osarios en las tum- 


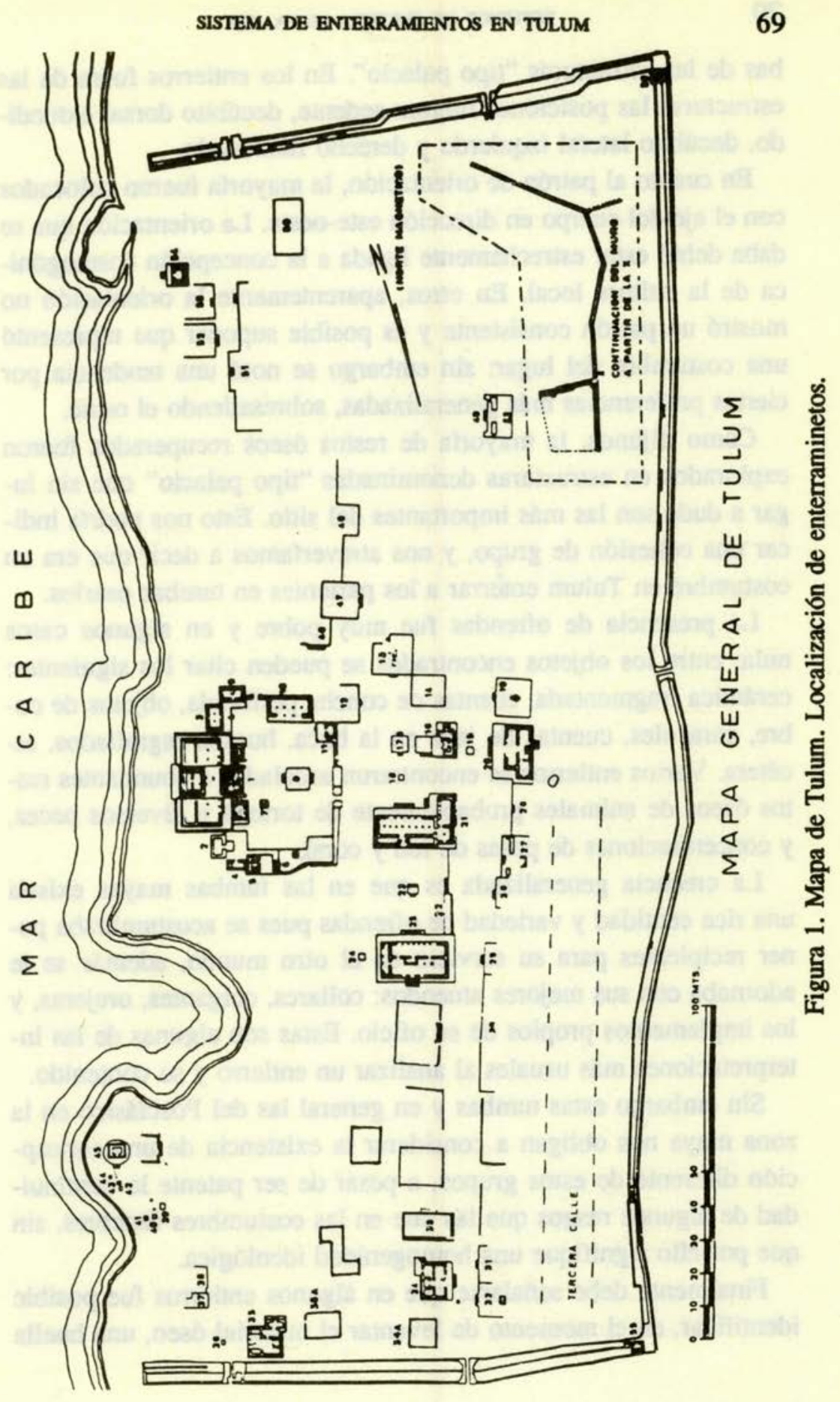

Estudios de Cultura Maya. Vol. XIX, 1992

Instituto de Investigaciones Filológicas/

Centro de Estudios Mayas, UNAM

ISSN 0185-2574 
bas de las estructuras "tipo palacio". En los entierros fuera de las estructuras las posiciones fueron: sedente, decúbito dorsal extendido, decúbito lateral izquierdo y derecho flexionado.

En cuanto al patrón de orientación, la mayoría fueron colocados con el eje del cuerpo en dirección este-oeste. La orientación que se daba debió estar estrechamente ligada a la concepción cosmogonica de la cultura local. En otros, aparentemente la orientación no mostró un patrón consistente y es posible suponer que represento una costumbre del lugar, sin embargo se notó una tendencia por ciertas preferencias más generalizadas, sobresaliendo el oeste.

Como dijimos, la mayoría de restos óseos recuperados fueron explorados en estructuras denominadas "tipo palacio" que sin lugar a duda son las más importantes del sitio. Esto nos podrfa indicar una cohesión de grupo, y nos atreverfamos a decir que era un costumbre en Tulum enterrar a los parientes en tumbas osarios.

La presencia de ofrendas fue muy pobre y en algunos casos nula; entre los objetos encontrados se pueden citar los siguientes: cerámica fragmentada, cuentas de concha perforada, objetos de cobre, caracoles, cuentas de jade en la boca, huesos esgrafiados, etcétera. Varios entierros se encontraron asociados a abundantes restos 6 seos de animales probablemente de tortuga y diversos peces, y concentraciones de pesas de red y coral.

La creencia generalizada es que en las tumbas mayas existra una rica cantidad y variedad de ofrendas pues se acostumbraba poner recipientes para su servicio en el otro mundo, además se le adornaba con sus mejores atuendos: collares, colgantes, orejeras, y los implementos propios de su oficio. Estas son algunas de las interpretaciones más usuales al analizar un entierro y su contenido.

Sin embargo estas tumbas y en general las del Posclásico en la zona maya nos obligan a considerar la existencia de una concepción diferente de estos grupos, a pesar de ser patente la continuidad de algunos rasgos que las une en las costumbres fúnebres, sin que por ello signifique una homogenidad ideológica.

Finalmente debe señalarse que en algunos entierros fue posible identificar, en el momento de levantar el material oseo, una huella 
que sugiere el que se haya hecho una pequeña fogata sin que los restos hayan sido realmente afectados.

Quisiéramos por último señalar que en este trabajo no nos ocuparemos del estudio osteologico, solo nos ocuparemos de aquellas características morfologicas sobresalientes que pudieron ser apreciadas durante las exploraciones, ya que el estudio detallado de los mismos ha sido realizado por las antropologas físicas Magalf Daltabuit y Magalf Civera.

Como se sabe, la práctica de alterar la morfología extema del cuerpo humano estuvo muy difundida en épocas prehispánicas. A pesar de que los cráneos se encontraban en un estado de conservacion regular, en todos aquellos casos en que el deterioro no fue mayor se constató una deformación craneana de tipo tabular erecta (Lámina 1), práctica que parece haber sido frecuente durante el Posclásico (Romano 1974).

Landa (1978) escribio ... que tenian sus cabezas y frentes llanas, hecho también por sus madres, por industria, desde niños. Por su parte, Ruz (1968) apunta que esta práctica parece tener mayor incidencia en las tierras bajas; y que en el área central es más frecuente que en la septentrional, en donde estos hallazgos pueden considerarse escasos.

Respecto a la mutilación dentaria, tal parece que no fue muy utilizada por este pueblo, pues solamente se presentó en dos o tres entierros y en hallazgos aislados.

Consideraciones generales sobre las posibilidades de inferencia en los entierros

Se tratará de utilizar el potencial que tiene el análisis de las costumbres funerarias, como uno de los indicadores de la base economica y social del grupo.

En el transcurso de los afios, los enfoques sobre el particular han cambiado. Binford (1971) y Saxe (1971) enfatizan que el potencial de las evidencias mortuorias tiene grandes posibilidades 


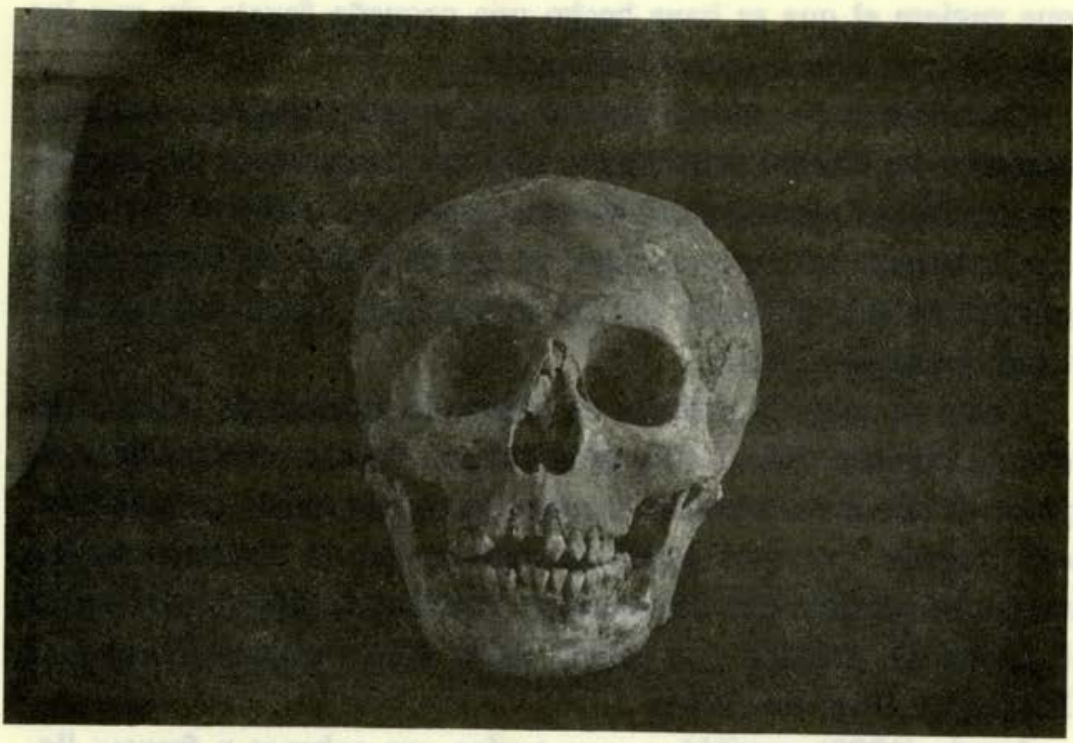

Lámina 1. Deformación craneana del tipo tabular erecto.

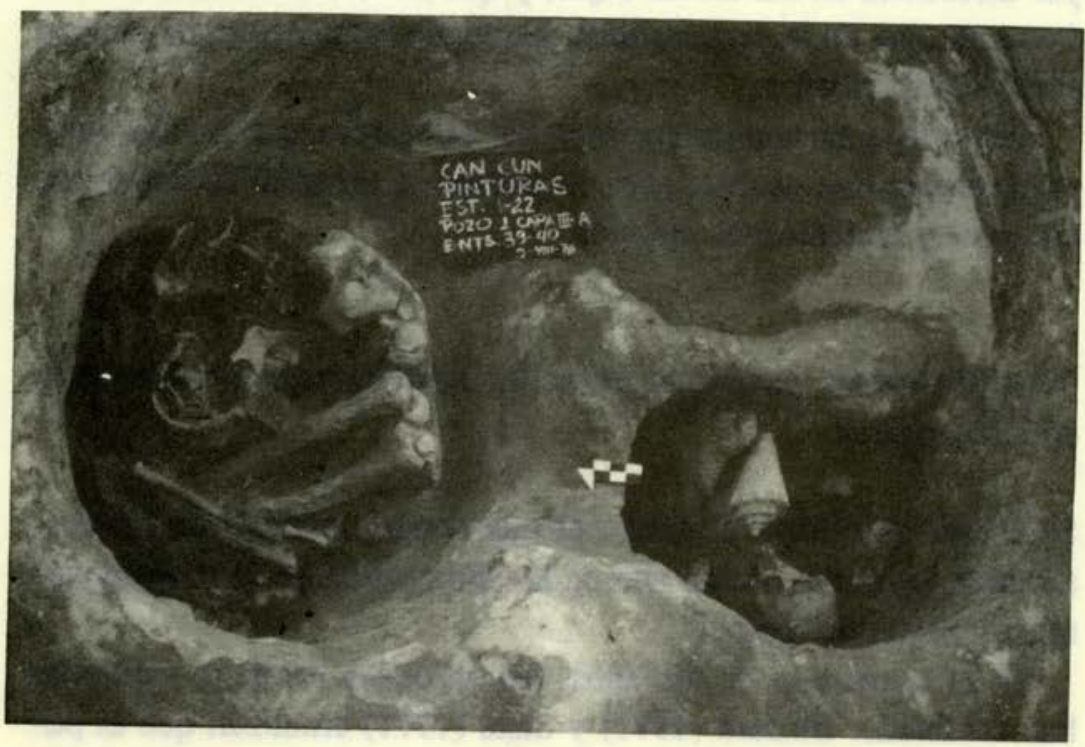

Lámina 2. Entierro primario directo, en hoyos circulares sobre el piso de la estructura.

Estudios de Cultura Maya. Vol. XIX, 1992

Instituto de Investigaciones Filológicas/

Centro de Estudios Mayas, UNAM

ISSN 0185-2574

http//www iifilologicas, unam mx/estculmaya/ 
para explicar el sistema social del cual formaban parte los individuos en el curso de su vida. Una forma de identificar los conjuntos de entierros es la propuesta de Binford, en la cual de acuerdo con la clasificación de atributos mortuorios se determina el rol que tuvo en vida el difunto dentro de la estructura o sistema social, condición que le es reconocida y considerada en la muerte por parte del grupo al que pertenecia.

Brown (1981) propone tres argumentos para el análisis de rangos sociales: el primero se refiere al principio del gasto energético y nos dice que el rango social del individuo enterrado está correlacionado con la cantidad o volumen de energfa canalizada a los ritos de enterramientos. E1 segundo se refiere a la identificacion de artefactos y atributos como símbolo de autoridad y poder dentro de una sociedad. Le da gran importancia a la ubicación del entierro en un espacio exclusivo y relevante socialmente. $Y$ por último se refiere a la composición demográfica de la población de los entierros.

Algunos autores mexicanos también se han preocupado intensamente por el tema (sobre todo antropologos físicos y arqueologos), a los cuales serfa difícil enumerar. Se recomienda para el análisis de este tipo utilizar un enfoque antropológico y que los resultados se apoyen en indicadores tales como los artefactos, lugar residencial del grupo, prácticas mortuorias y también en otras dimensiones arqueologicas, tales como el patrón espacial de las estructuras al interior de un sitio, y la distribución espacial de los mismos en una región dada.

Para el área maya tenemos el estudio de Alberto Ruz L. (1968) sobre costumbres funerarias, en donde además de hacer una síntesis de los sistemas de enterramientos, plantea la posibilidad de realizar inferencias no sólo sociales, sino también ideológicas, tecnologicas y económicas.

A continuación tomando algunas de las ideas de los autores citados, trataremos de resumir las posibles inferencias que podrían sacarse a partir del estudio de los enterramientos humanos. 
Inferencias tecnológicas

La construcción de algunas tumbas requirió conocimientos previos de ingeniería y arquitectura, pues tenían que ser planeadas de manera clara y precisa antes y/o durante la realización del edificio.

El desarrollo tecnológico, económico y cultural que presenta la civilización maya en el curso de su historia, tiende a reflejarse en las prácticas funerarias.

Es difícil trazar para todo el territorio maya, y aún para algunas áreas y regiones, una evolución que abarque desde los entierros sencillos del Preclásico con escasas ofrendas o sin ellas, hasta los sepulcros más elaborados con ricas ofrendas del Clásico Tardío; ya que la elaboración de las tumbas no sigue siempre una línea paralela a los avances arquitectónicos. Además la visión varfa de un sitio a otro según el ritmo evolutivo local de la cultura.

Como dijimos, hay entierros sencillos en cistas, fosas y cámaras funerarias en todos los periodos y regiones, esto es debido a que la diversidad de tipos de enterramientos corresponde a diferencias sociales más que al desarrollo cultural. De todos modos, es significativo que durante el Preclásico predominen los entierros sencillos y no las tumbas ricas que comienzan con el final de este periodo o el Protoclásico, y que las tumbas más suntuosas pertenecen al periodo de mayor brillantez, el Clásico Tardío.

Para el Postclásico parece ser que la técnica constructiva de los periodos anteriores se mantiene; sin embargo la disposición de los restos óseos es diferente como se podrá apreciar en los datos reportados para Tulum; en cuanto a la riqueza de ofrendas se puede decir que es nula o muy pobre.

\section{Inferencias económicas}

A partir de los elementos encontrados en las tumbas podemos pensar que existio un contacto continuo, extensivo y prolongado de pueblos de todas las regiones en que las influencias viajaron en todas direcciones, dejando como secuela la difusión de técnicas, 
estilos y costumbres que propiciaron y favorecieron el desarrollo de los. pueblos involucrados.

Todas estas inferencias pueden ser válidas, gracias a las ofrendas que se encuentran en los enterramientos, asf como también en la arquitectura de algunas tumbas que nos refieren contactos con otras regiones por medio de la cerámica, metal, obsidiana, conchas, etcétera.

\section{Inferencias sociales.}

La presencia de disțintos estratos sociales se refleja con frecuencia en los entierros. La costumbre de inhumar a los muertos en un monumento refleja e implica una sociedad estratificada en' la cual se daba una diferenciación social bien establecida. Debió estar integrada por un estrato con mayor acceso a los recursos que favorecf́a el dispendio suficiente para la construcción del monumento fúnebre empleando al grupo menos favorecido.

También podría tratarse desde una perspectiva ideológica, en la que intervendra la diferenciación social como factor obligado por conceptos religiosos. En este sentido, el gobernante representaria un símbolo sagrado al cual habría que distinguir hasta después de su muerte con la intención de perpetuar su presencia.

Otros de los problemas que enfrenta el arqueologo ante el hallazgo de gran cantidad de restos óseos, es el de tratar de dilucidar las causas de la mortalidad en la población de la región o sitio que estudia. Examinar las variaciones de la tasa de mortalidad por periodos o fases, así como en relación al sexo y edad. El aumento de la mortalidad hubiera podido indicar una época de privaciones alimenticias, plagas o epidemias. La disminución, por el contrario, un periodo de prosperidad. Un índice mayor de mortandad para los hombres pudiera estar asociado a tiempos de guerra. Tales aspectos son imposibles de estudiar con nuestra información; sin embargo se pueden hacer algunas inferencias generales.

Para algunas tumbas se ha señalado la posibilidad de que fueran utilizadas como receptorios familiares usándose por varias genera- 
ciones; solo así se explicaria la presencia de varios tipos distintos de restos óseos en una misma tumba; éste serfa el caso más cercano al que nos adherirfamos para Tulum.

Algunos de los elementos que nos sirven como parámetros en ese sentido son básicamente: la cantidad de restos óseos explorados y la disposición de los mismos, que al parecer fueron colocados en el interior de las tumbas en diferentes ocasiones, la ubicación del entierro, el tipo de sepultura, la cantidad y calidad de las ofrendas, la presencia o ausencia de acompañantes sacrificados, etcétera.

Es así como la gente común se enterraba dentro o cerca de las plataformas que servían de basamentos a sus casas, tal como lo informaron los cronistas, y como la arqueología pudo comprobarlo en los sitios en que se llevaron a cabo excavaciones en las zonas habitacionales. Por el contrario, los individuos que fueron enterrados en los edificios dedicados al culto o en residencias más elaboradas que las simples chozas y situadas en los límites del centro ceremonial, debieron pertenecer generalmente a las clases dominantes, y su jerarquía - civil o religiosa - determinarfa el sitio de su entierro. Podemos pensar en una escala de importancia que va desde el entierro al pie de un edificio o debajo de una plaza, hasta la cripta construída exprofeso al centro de una estructura piramidal para un gran Señor.

\section{Inferencias ideológicas}

El modo de enterramiento y los objetos que fueron puestos junto con el difunto debieron ser colocados persiguiendo algún proposito específico; esto incluye la ubicacion y el tipo de inhumación.

El conjunto expresa un simbolismo que solo podría interpretarse adecuadamente al penetrar en la ideología de la cultura, aspecto intangible que es imposible de conocer una vez que desapareció la sociedad creadora sin dejar testimonios orales y/o escritos.

De alli la necesidad de buscar incansablemente ese pensamiento que llevó a los hombres para explicar su existencia y creencias 
con respecto a sus muertos a través de los restos materiales dejados por ellos. $Y$ aún asi, de ninguna manera podrán reflejar fidedigna y fielmente las concepciones que se tenfan hacia la vida y el universo dentro del cual se desarrolla el hombre.

Posiblemente como arqueologos hemos dejado a un lado algunos de estos puntos por parecemos diff́ciles de manejar o para hacerlo posteriormente cuando tengamos estudios de antropologia ffsica; pensamos que podemos abordar algunos aspectos tales como los ideologicos, económicos y sociales auxiliándonos de las fuentes historicas para poder entender mejor lo que excavamos. De alli la preocupación de abordar el tema y dar una explicación de los osarios de Tulum.

Sistema de enterramientos en la costa oriental

Hasta ahora no se ha podido definir un sistema de enterramiento característico de la costa oriental de Quintana Roo. Existen reportes sobre enterramientos en Cobá, Can Cun, El Meco, Playa del Carmen, Tancah, Xelhá, Kantunilkin, Cozumel y Tulum, entre otros.

En Cobá se encontraron entierros del Posclásico dentro de las estructuras habitacionales y en general las tumbas coinciden con el eje central de las casas. También existen reportes de entierros colectivos.

En El Meco se exploraron tres entierros, todos del Posclásico. La posicion fue flexionada, sedente o de cúbito lateral (Andrews y Robles 1986).

En Playa del Carmen fueron explorados 11 entierros durante los trabajos de investigación que se llevaron a cabo y se encontraron dos tipos: entierros individuales o colectivos y los procedentes de un osario (Márquez 1982).

El predominio fue de entierros primarios de los cuales 7 fueron indirectos. Los entierros en su mayoría se encontraron dentro de las casas debajo de los pisos, todos los esqueletos fueron flexionados y 7 estaban en cistas de piedra. 
Algunas de las tumbas coinciden con eje central de la casa. Otra característica es que algunas de ellas presentaron un estucado interior (Márquez 1982).

En Can Cun el tipo de entierro que predomino fue el directo primario. La mayor parte de los mismos proceden del periodo Posclásico y fueron realizados en el interior de las estructuras. Lo característico de éstos fue que en el piso se hicieron hoyos circulares (lámina 2) en donde se depositaba a los individuos flexionados, a diferentes profundidades (Ramos 1978).

En Tancah también se han reportado enterramientos. En las estructuras dos y siete se encontraron amontonamientos de piedras que posiblemente fueron una tumba. Existen reportes de enterramientos coloniales con diversas posiciones, reportadas por A. Miller y Farriss (1985).

En Cozumel James Kennedy abrio varias tumbas de las cuales no se sabe su localización y encontro lítica, implementos de cobre, figuras con cabeza, imágenes de tortugas, incensarios y vasijas de cerámica.

En Cozumel parece que se han excavado varios osarios, pero la información es vaga.

Lothrop (1924) dice que se puede encontrar gran cantidad de tumbas de bóveda en Tulum, aparentemente en los montículos plataformas.

En la estructura 13 aparecieron dos tumbas que tenfa techo de b6veda (Lothrop 1924:91); éstas eran rectangulares.

La estructura 19 tiene como característica principal una tumba cruciforme (lámina 3), con las paredes verticales y piso estucado; el techo era de grandes losas de piedra. Tanto el techo como el piso de los brazos sur y norte son más bajos que los del este y el oeste. No se pudo determinar la posición del cuerpo; se encontró cerámica rota y huesos de animales; los huesos que se identificaron fueron de tiburon, pez gato, iguana, cocodrilo, paloma, pavo, pecarí, conchas y moluscos (Lothrop 1924:97).

En la estructura 22 se encontraron 2 tumbas en la parte norte y sur del montículo; su forma era abovedada. La del lado norte tenía 
una bóveda muy bien construida y estaba parcialmente excavada; sólo se encontró algo de cerámica. La del lado sur tenía media b6veda construida contra una pared recta (Lothrop 1924:102).

En la estructura 23 Lothrop creyo que había una tumba. mas no la excav6́ y supuso que era abovedada.

Miguel Ángel Femández (1945) encontró un esqueleto humano al pie del templo número nueve, pero no informa cómo se encontơ ni su posición.

Así es que existen varios reportes de enterramientos individuales, tumbas y cistas para la costa oriental de Quintana Roo, péro la información, en tệrminos generales, es fragmentaria y no fidedigna. Por tal motivo es diff́cil poder definir el sistema de enterramientos que se dio en la region. Con las exploraciones que se realizaron en Tulum se localizaron varias tumbas, cistas o fosas y enterramientos; aunque la muestra no es muy grande pensamos que puede ser representativa para poder definir el sistema de enterramientos en Tulum.

El sistema de enterramiento en Tulum.

La demás gente principal hacia a sus padres estatuas de madera a las cuales dejaban hueco el colodrillo, y quemaban alguna parte de su cuerpo y echaban allí las cenizas y tapábanlo; y después desollaban al difunto el cuero del colodrillo y pegábanselo allí, enterrando los residuos como tenía de costumbre, guardaban estas estatuas con mucha reverencia entre sus ídolos (Landa 1978:59).

Con las exploracionés realizadas durante 1982 pensamos que tenemos una idea general sobre los sistemas de enterramiento en Tulum, ya que tuvimos la oportunidad de explorar gran parte del sitio y con ello se localizaron tumbas, cistas, fosas y enterramientos individuales; se describirán primero las tumbas y fosas, después las cistas y por último los enterramientos individuales. 
Tumbas y fosas.

Por la homogeneidad arquitectónica que presenta Tulum uno pensaŕa que se darfa también en el sistema de enterramientos. Sin embargo, al compararlos existe una gran variedad. Las tumbas no son iguales, existen cruciformes, rectangulares y cuadrangulares con o sin escaleras para bajar, con boveda y losas; y aun dentro de las cruciformes existen sus variantes.

A continuacion haremos una descripción de las estructuras en donde fueron encontradas las tumbas y cistas con restos óseos.

\section{Estructura 20}

Se localiza casi frente al Templo de los Frescos y se levanta sobre un basamento asentado directamente sobre la laja; para ascender al edificio existen escalinatas con alfardas en los lados oriente y norte (Lámina 4).

Toda la estructura tenía techo plano sostenido con vigas. En la fachada principal todavía se pueden apreciar restos de estuco que representaba posiblemente un personaje. El dintel que sostenía la escultura estuvo soportado por dos columnas que sirvieron de entrada al primer cuarto, en donde se encontro el acceso a la tumba. Este tenía todavía restos de pintura y banquetas. Existe un puerta que comunica con el segundo cuarto, está coronada por un nicho en el que aún pueden apreciarse restos de una figura del llam. Dios Descendente. Como detalles arquitectónicos se aprecian bàquetas, altar central y dos puertas, una al lado norte y otra al oeste.

La exploración se realizó con la intención de comprobar si verdaderamente existía una tumba al centro de las edificios. Se hizo un pozo entre las dos banquetas, en donde el piso estaba bastante destruido, y se encontraron piedras y losas que formaban las paredes y la parte superior de la misma, al levantar las lajas se pudo apreciar que eran el acceso a la tumba que, como característica gentral de Tulum, estaba obstruida por tierra, piedras y restos 
oseos. Este derrumbe tapaba las escaleras y llegaba hasta la base, que tiene una planta rectangular y al fondo había una pequeña banqueta 0 altar.

La exploración de la tumba se hizo por medio de niveles artificiales, que fueron diez en total (Figura 2); con los primeros se liberaron los escalones de la entrada y se exploraron restos oseos de costillas, vértebras, falanges y dientes con mutilación; además fragmentos de incensarios y grandes piedras; no se encontro ninguno en posición anatómica. En el nivel octavo se logro descubrir el tercer escalón y nos permitió realizar la exploración horizontal; en éste apareció una carita con su tocado color azul y decoración al patillaje, además cerámica y un caracol cortado (Figura 3).

El décimo nivel abarca todo el interior de la tumba y all se encontraron falanges, fragmentos de costillas, fémures, cráneos, etcétera; entre otros materiales se tienen restos de cerámica Paamul inciso, fragmentos de incensarios, una cuenta de jade y concha. El material oseo en general se puede considerar escaso (Figura 4).

La tumba se localiza al centro y su entrada está entre las banquetas del primer cuarto, queda bajo el altar, y el acceso tenía que ser por arriba, rompiendo el piso hasta llegar a las losas que cubrian la entrada.

La forma, como dijimos, es rectangular y la orientación es casi la misma que la del edificio. Creemos que ésta fue planeada y construida conjuntamente con él, aunque existe la posibilidad de que perteneciera a la etapa constructiva anterior, como es el caso de este edificio, que tiene varias etapas.

$\mathrm{Al}$ parecer las tumbas eran abiertas en diferentes ocasiones para poner restos óseos en su interior, al principio los huesos fueron depositados con cuidado y cierto orden en la banqueta que estaba al fondo, posteriormente se fue llenando todo el interior y por último se cubría con restos óseos y fragmentos de algunos incensarios y vasijas; siendo hasta el último momento cubiertas las escaleras que servían de acceso a la tumba con pedacería de huesos, tiestos y piedra.

Se entraba por medio de un orificio que quedaba abierto al qui- 

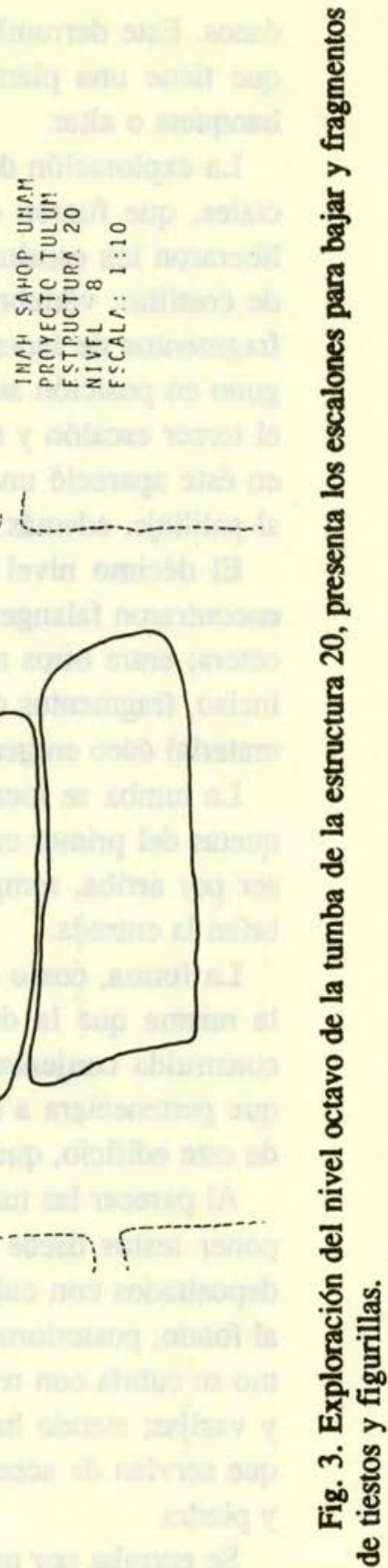

Estudios de Cultura Maya. Vol. XIX, 1992

Instituto de Investigaciones Filológicas/

Centro de Estudios Mayas, UNAM 


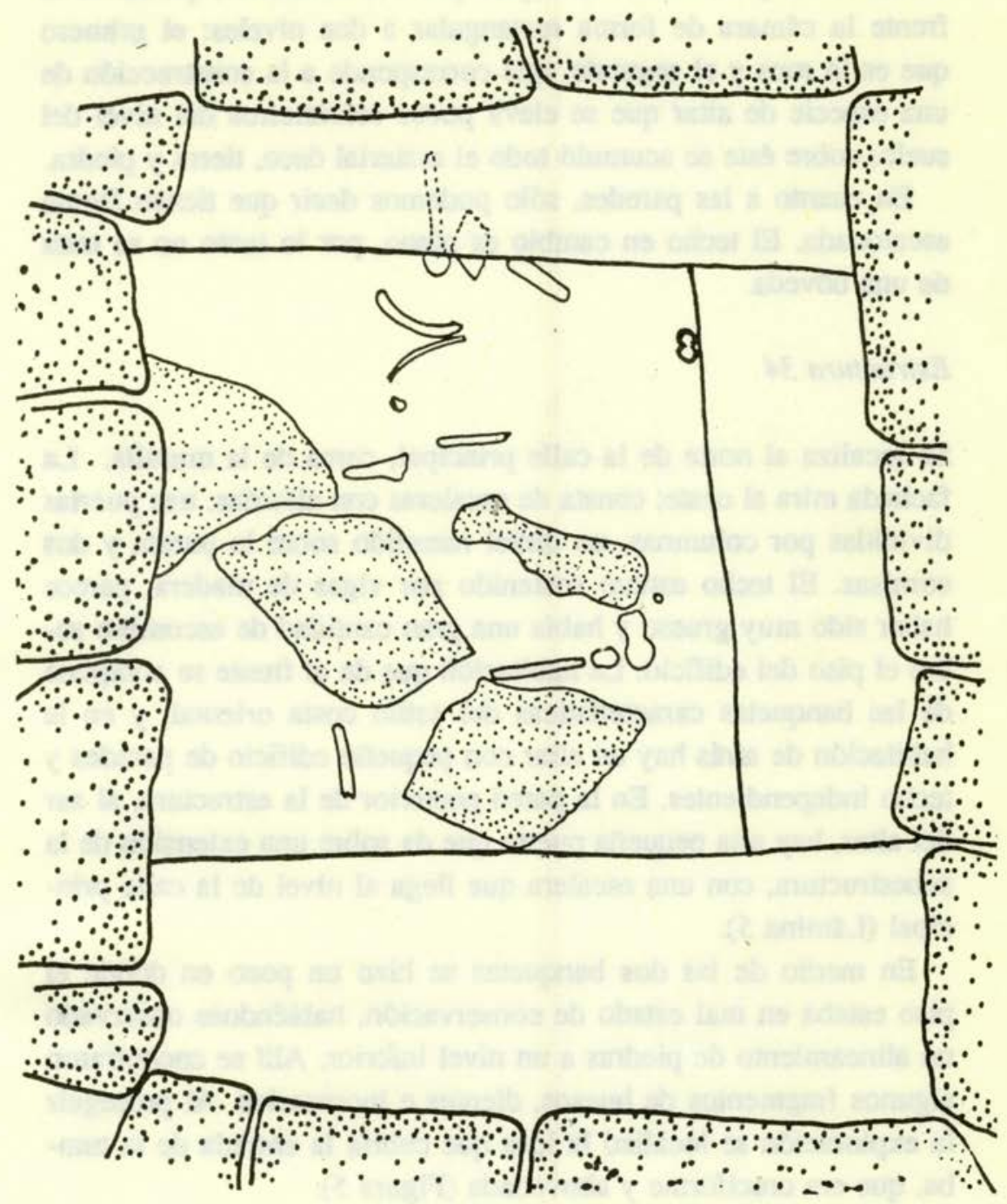

INAH SAHOP UNAM

PROYECTO TULUM

ESTRUCTURA 34

NIVEL 1

ESCALA: $1: 10$

Fig. 5. Entrada a la tumba de la Estructura 34. 
tar las losas, y al interior se bajaba por tres escalones, quedando al frente la cámara de forma rectangular a dos niveles: el primero que es la roca y el segundo, que corresponde a la construccion de una especie de altar que se eleva pocos centŕmetros del nivel del suelo; sobre éste se acumulo todo el material oseo, tierra y piedra.

En cuanto a las paredes, solo podemos decir que tienen forma escalonada. El techo en cambio es plano, por lo tanto no se trata de una bóveda.

\section{Estructura 34}

Se localiza al norte de la calle principal, cerca de la muralla. La fachada mira al oeste; consta de escaleras con alfardas, tres puertas divididas por columnas, un dintel remetido sobre la puerta y dos comisas. El techo estuvo sostenido por vigas de madera, parece haber sido muy grueso y habra una gran cantidad de escombro sobre el piso del edificio. La habitación que da al frente se compone de las banquetas características del estilo costa oriental, y en la habitación de atrás hay un altar con pequeño edificio de paredes y techo independientes. En la pared posterior de la estructura, al sur del altar, hay una pequeña puerta que da sobre una extensión de la subestructura, con una escalera que llega al nivel de la calle principal (Lámina 5).

En medio de las dos banquetas se hizo un pozo en donde el piso estaba en mal estado de conservacion, habiéndose observado un alineamiento de piedras a un nivel inferior. All se encontraron algunos fragmentos de huesos, dientes e incensarios. Al proseguir la exploración se localizó la losa que cubría la entrada de la tumba, que era cruciforme y abovedada (Figura 5).

La orientación se conforma con la del edificio (este-oeste), aunque existe una diferencia mínima (Figura 6). La altura máxima en su parte central es de $1.60 \mathrm{~m}$ y el ancho de $2.80 \mathrm{~m}$ de la pared norte a la sur, $2.10 \mathrm{~m}$ de la pared este a la base de las escaleras, y de $1.10 \mathrm{~m}$ de ahí a la pared oeste, es decir, el ancho total de las escaleras. Al este de la tumba existe una banqueta y el piso estaba 


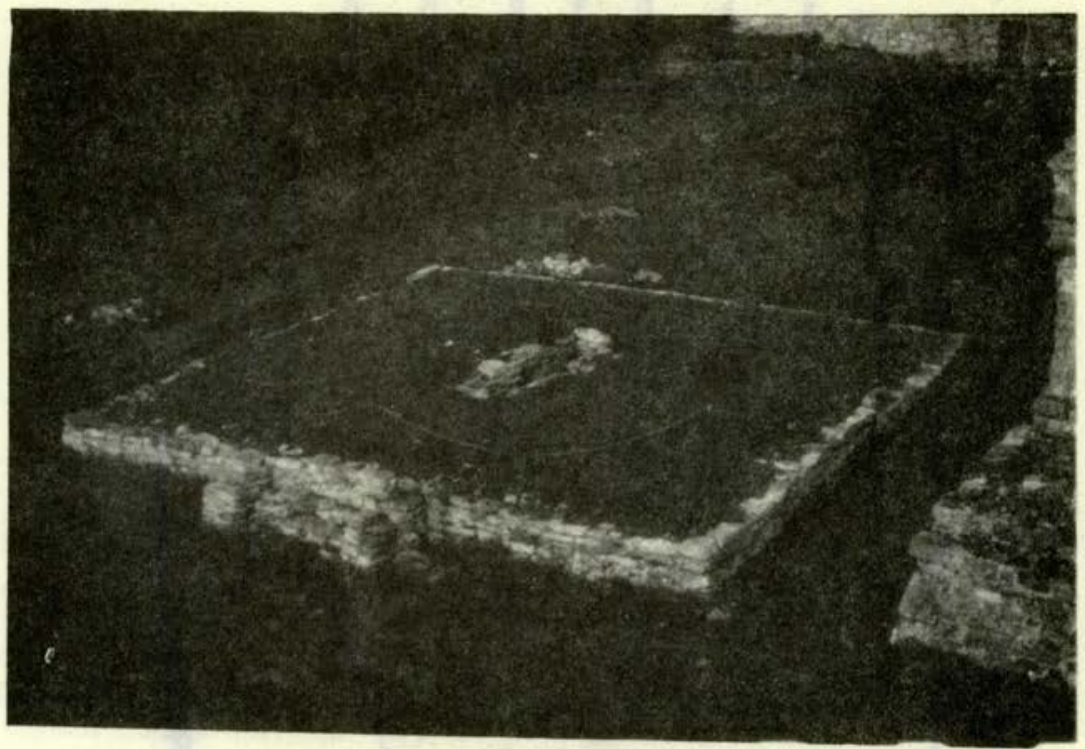

Lámina 3. Estructura 19 con la tumba cruciforme al centro.

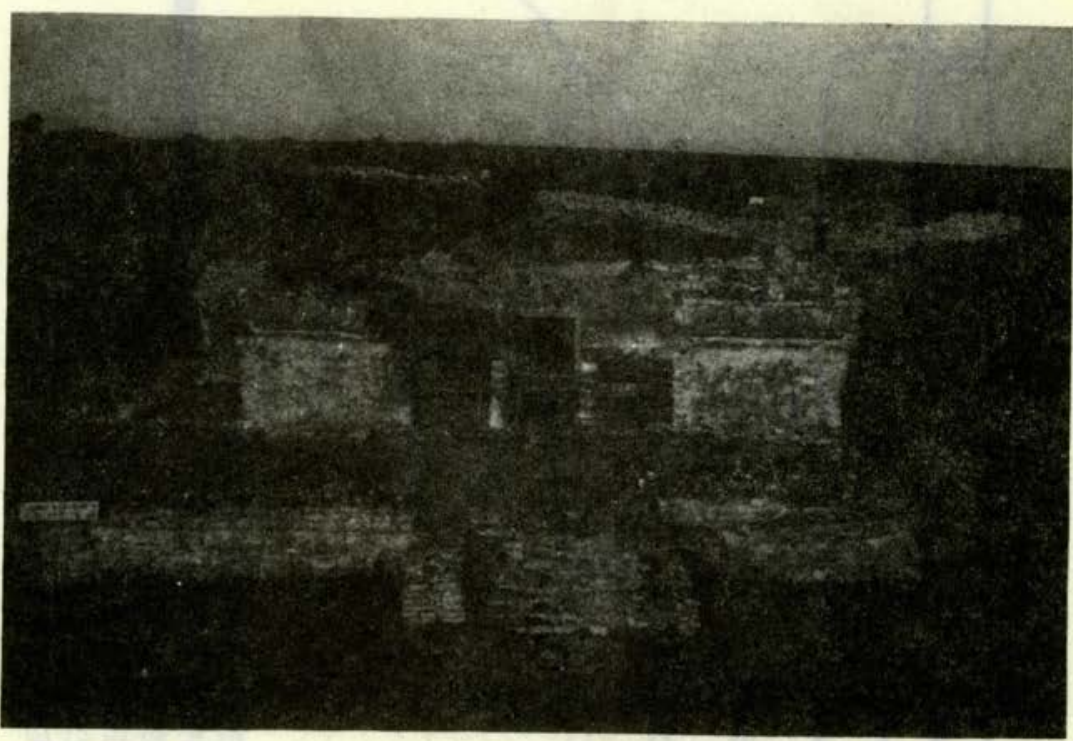

Lámina 4. Estructura 20, del tipo llamado palacio, y que al centro tiene una tumba.

Estudios de Cultura Maya. Vol. XIX, 1992

Instituto de Investigaciones Filológicas/

Centro de Estudios Mayas, UNAM

ISSN 0185-2574

http://www iifilologicas unam.mx/estculmava/ 


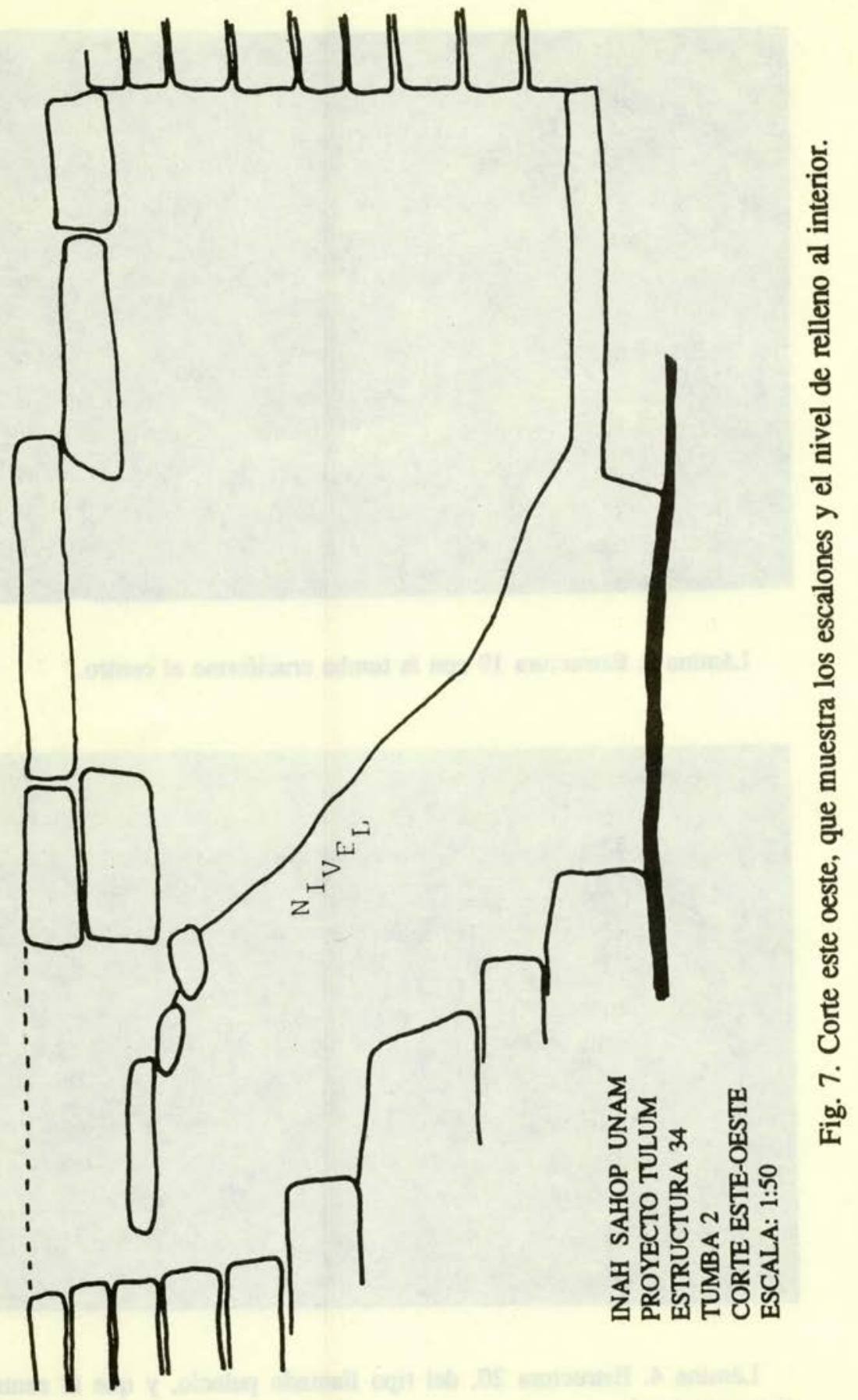

Estudios de Cultura Maya. Vol. XIX, 1992

Instituto de Investigaciones Filológicas/

Centro de Estudios Mayas, UNAM 
cubierto por una capa de tierra, piedras, fragmentos de ceramica y huesos humanos.

La exploración se realizo por niveles artificiales; en total fueron 12 (Figura 7). Se supone que fue abierta en varias ocasiones y allr depositaban los restos humanos en diversos momentos. En general los restos óseos no tienen posición anatómica; sólo en los tres últimos niveles aparecieron tres individuos mutilados (Figura 8), pero la mayoría siguieron siendo huesos largos, costillas, huesos de manos y pies, vértebras y muchos dientes con mutilación.

La exploración de los niveles uno, dos y tres, dejo al descubierto los escalones que sirvieron para bajar a la tumba, el material que apareció fue cerámica, fragmentos de obsidiana y de huesos largos, etcétera. A partir del nivel cuatro la exploración se realizo por secciones: ala norte, sur, este y oeste. Aquí solo presentamos los últimos niveles por ser los más interesantes. En el nivel diez se encontró además de una gran cantidad de huesos largos y fragmentos, un torso y dos pies en posición anatómica; por la disposición del esternón se deduce que lo depositaron en posicion ventral. En el nivel once apareció el cuarto y último escalon, aqui también aparece un dorso en posición anatómica, por lo que creemos que fue mutilado, el material óseo es abundante, lo mismo que el de cerámica y huesos de animal. El nivel doce abarca toda la planta; para su exploración se dividió en cuatro alas: norte, sur, este y oeste. En el oeste se encontró un individuo cortado por la cintura, ya que aparecieron las 4 últimas vértebras lumbares, el sacro, el coxis, los 2 iliacos, 2 fémures, dos tibias, 2 estemones, los huesos tarsianos, metatarsos y las falangues de los 2 pies, todo ello en posición anatómica; su posición fue dorsal flexionado. Estos al parecer estaban separados del resto de huesos por piedras que se encontraban al centro. Aquí también se encontraron 13 cráneos, y como característica carecían de la mandíbula inferior y de las primeras vértebras (Figura 19). El material asociado fue de cerámica y un anillo de cobre trenzado. Al norte el material óseo era poco y fragmentado. El ala sur es más estrecha y obscura; aparecieron huesos largos sin posición anatómica; aquí se encontraron 5 


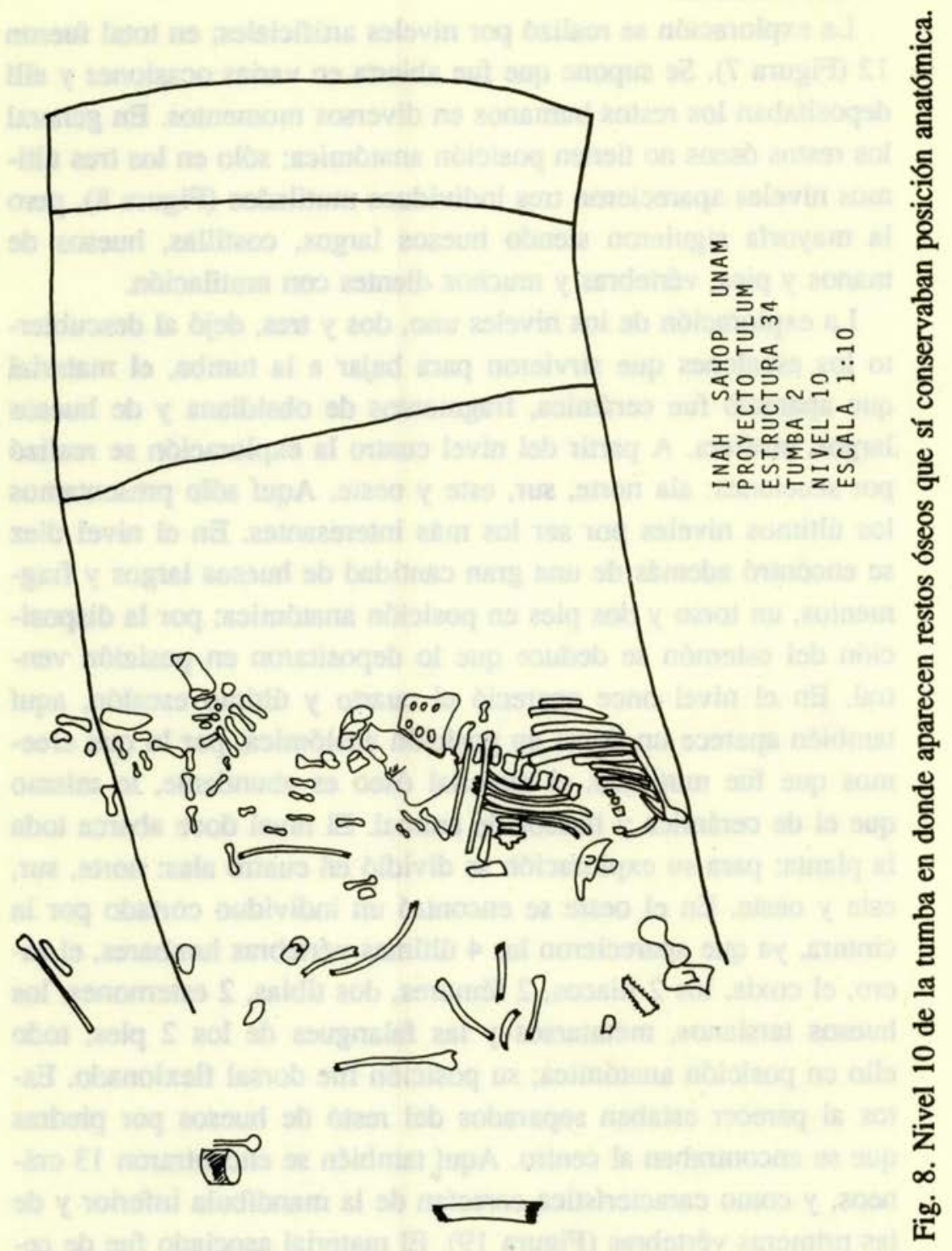




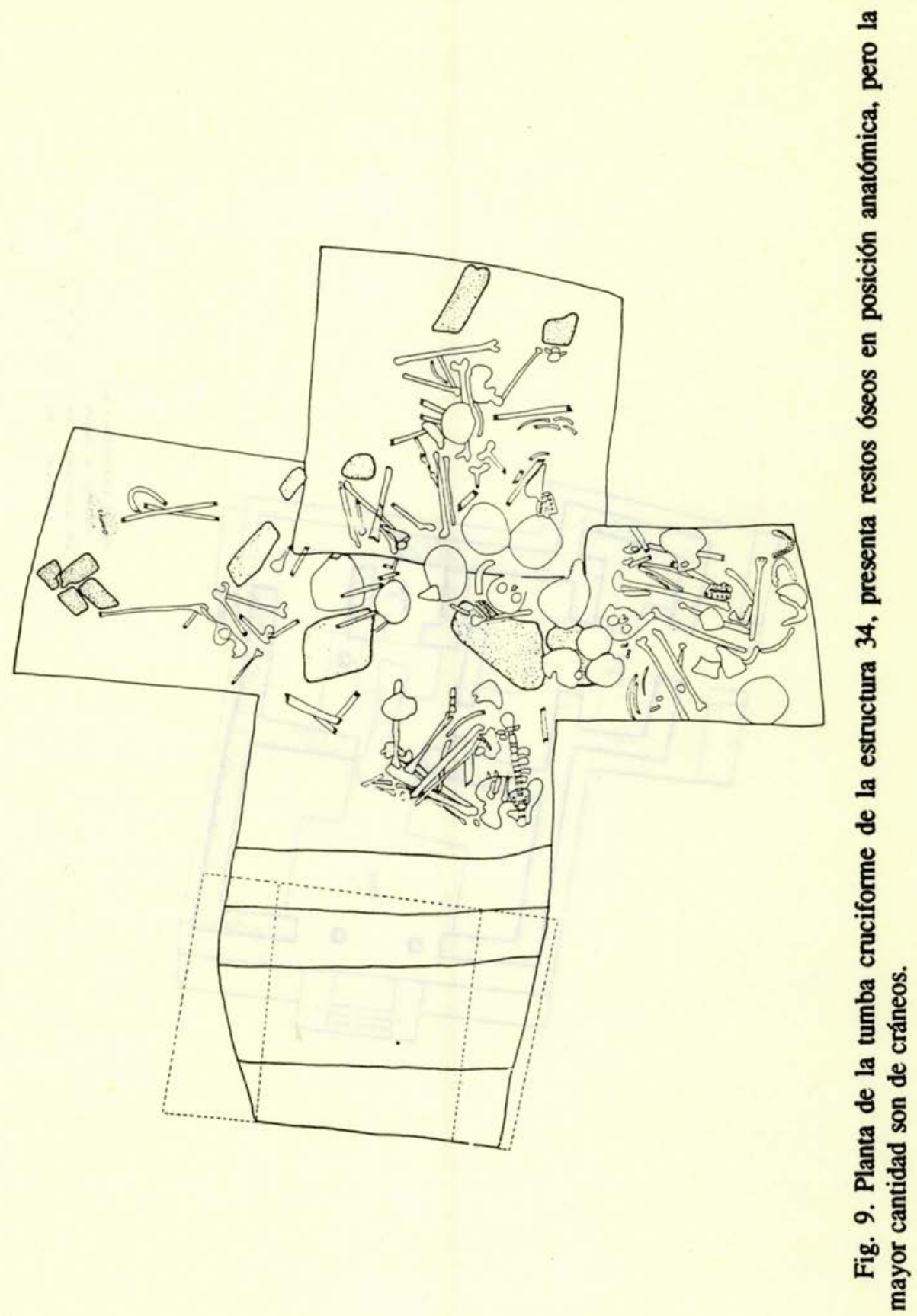

Estudios de Cultura Maya. Vol. XIX, 1992

Instituto de Investigaciones Filológicas/

Centro de Estudios Mayas, UNAM

ISSN 0185-2574 


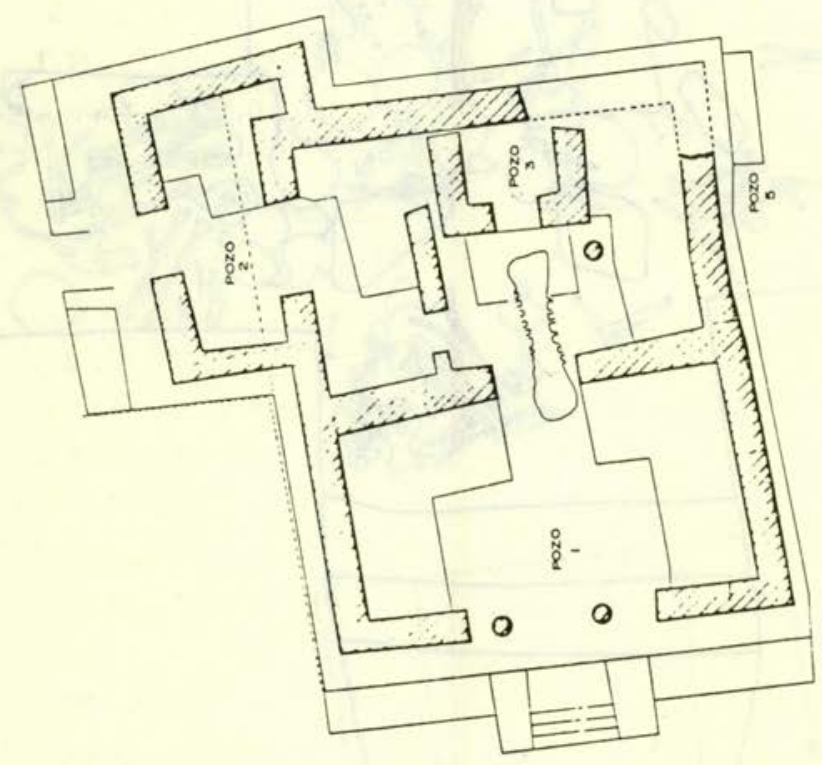

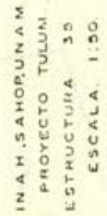


mandíbulas inferiores humanas y otra más de felino. En el ala este los restos óseos tenían una disposición particular: al centro se encontraron fragmentos de cráneos muy destruidos, en los extremos había 2 sacros con la parte más delgada orientada hacia el cráneo y formando un triángulo con otros dos huesos largos que iban de los sacros al cráneo. En el resto de la banqueta había huesos largos, costillas, una clavícula, un iliaco, todos ellos formando una ofrenda hacia el cráneo.

\section{Estructura 35}

Se localiza cerca de la muralla en el extremo noroeste, su fachada mira hacia el este (Lámina 6). El plano del edificio muestra dos períodos de construcción; el primero fue la erección de un edificio del tipo Palacio con dos cuartos largos y un santuario construido en la pared posterior del segundo cuarto. La segunda fase de la construcción se localiza casi sobre el techo del cenote y divide al cuarto original en dos partes, dando forma de " $L$ " al edificio.

La tumba se localiza en los cuartos A y B, alineada en el eje central (Figura 10); mide $3.10 \mathrm{~m}$ de largo por $1.25 \mathrm{~m}$ de ancho, con una profundidad de $1.05 \mathrm{~m}$ al este y $0.80 \mathrm{~m}$ en el oeste. Tiene techo de bóveda y forma ovalada; por su parte externa es un conglomerado de cal y piedra de tamaño regular, con caracol y coral. Por el interior tiene piedra trabajada que se coloca en forma de campana hasta lo más ancho que toca con el piso, en su parte superior la tapaban varias lajas (Figura 11).

Por estar el piso semidestruido se hizo un pozo estratigráfico entre los cuartos A y B; al limpiar los restos del piso se encontro la laja que formaba la parte superior de la tumba que estaba totalmente sellada. La exploración de la misma se hizo directamente, ya que no se veían en superficie restos óseos por estar cubiertos de tierra negra que al cemirse mostraba una gran cantidad de escamas y huesos de pescado. El registro fue cuidadoso, pues se llevaba por niveles, se numeraba y etiquetaba cada resto óseo antes de ser empaquetado, además de que se realizaron dibujos y registros fotográficos. 


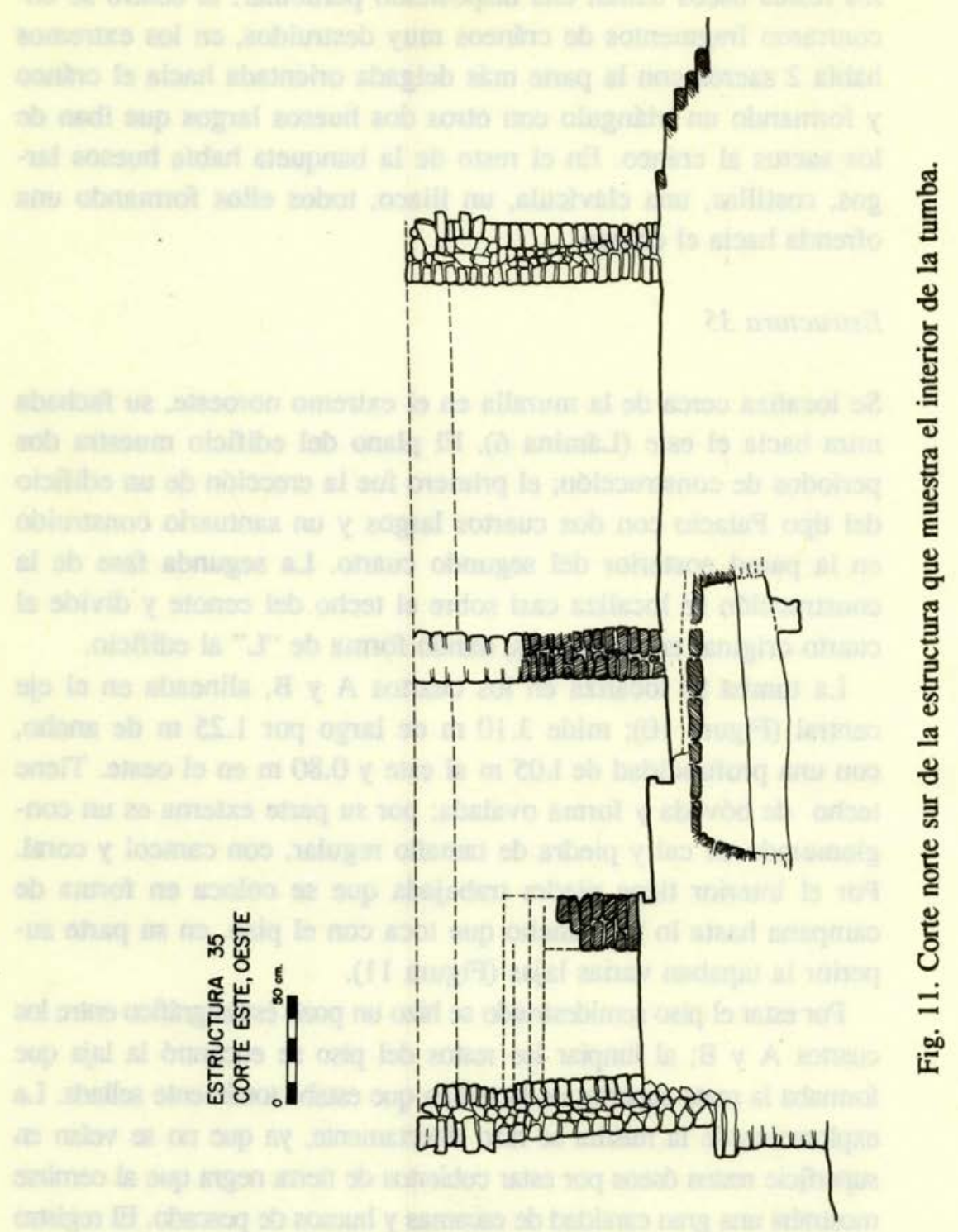


No tiene escaleras para bajar, su acceso se hacfa por la parte superior, rompiendo el piso, y su orientación corresponde a la del edificio (este oeste); ocupa la parte central del mismo.

Al abrirla fue desconcertante, pues no se vefa ningún resto oseo; todos estaban tapados por tierra negra, seguramente producto de filtraciones. Al iniciarse la limpieza se busc 6 en los restos oseos posición anatómica, pero se pudo observar que eran huesos dispersos y que su concentración fue en la parte este (Figura 12). En su mayoria son fragmentos de huesos largos, vértebras, costillas, iliacos, coxis etcétera. Hasta el nivel seis se ve que fue el último grupo de huesos echados en su interior; a partir de éste se ve claramente que existen otros dos grupos de deposicion de huesos: uno al fondo en el lado oeste y otro al este, que es el que tenía mayor número de huesos. A partir del nivel ocho, à simple vista pudo apreciarse que existran 4 deposiciones de material oseo: 1 al este y 3 al oeste. En este nivel se usó toda la tumba para depositar los huesos.

En el nivel quince se hizo la limpieza del piso y se encontraron fragmentos de huesos largos y vértebras, pero lo más interesante fue que aquí se encontro el mayor número de pesas de red, lo que nos indica que posiblemente se utilizaron redes para depositarlos (Figura 13).

Sobre la laja en el lado este de la tumba aparecio un hoyo natural de $0.30 \mathrm{~m}$ de profundidad; la tierra que salio era negra, revuelta con arena, restos de ceniza y tierra quemada, algunos huesos salieron quemados (Figura 14).

Plataformas: 29.

Se encuentra ubicada al oeste de la calle principal y está unida por un muro a la estructura 30; por el sur colinda con la estructura 28 y se encuentra exactamente enfrente de la estructura 25 , que está al este de la calle principal según el plano de Lothrop.

Nunca antes había sido trabajada; de alli que se hiciera un pozo al centro. Sus dimensiones fueron de 2 por $2 \mathrm{~m}$ y se excavó por 


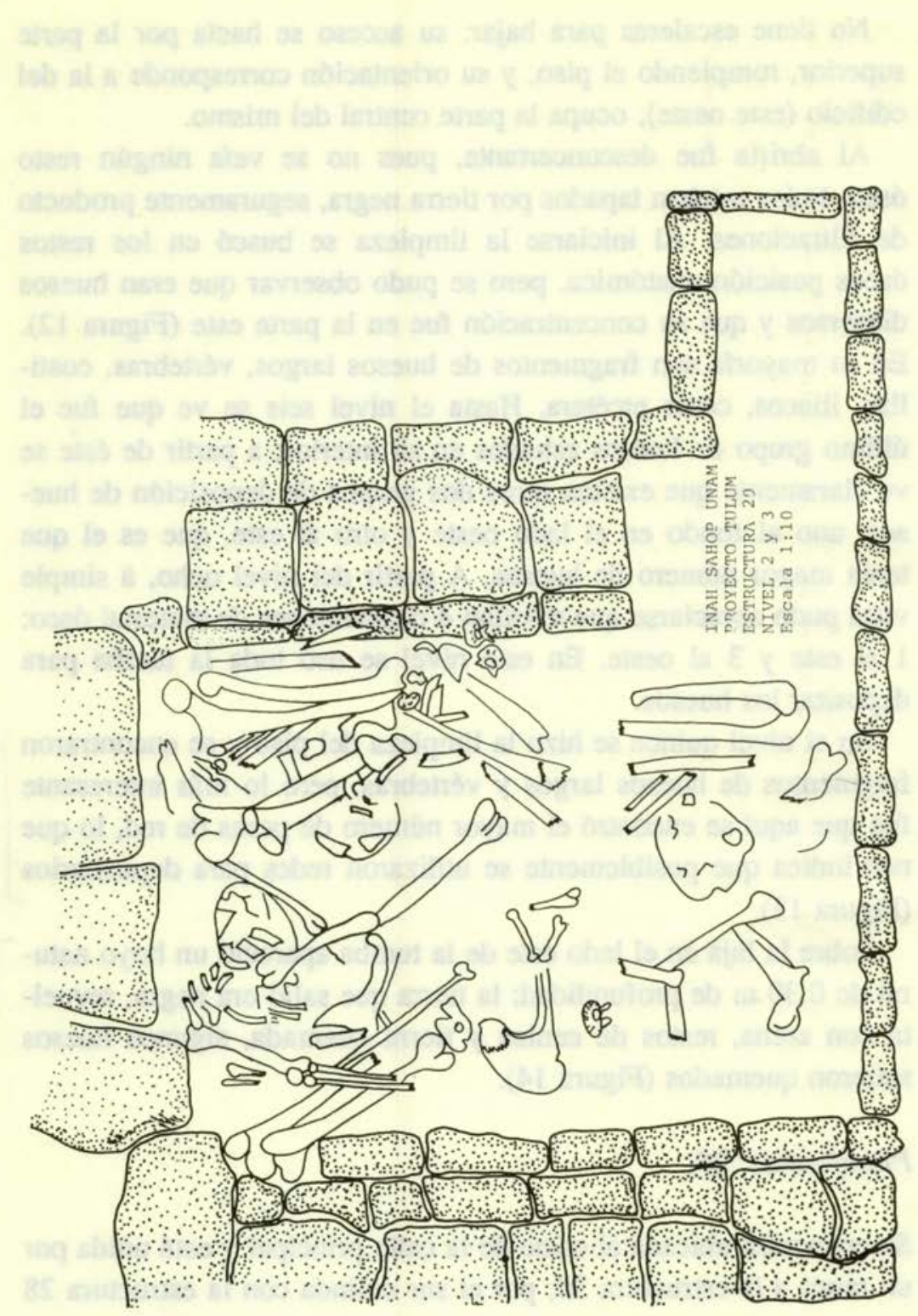


niveles métricos; en total fueron cinco. Hasta el nivel tres fue cuando aparecieron restos óseos en una prolongación que parecía una caja (Figura 15). En el nivel cinco aparecio gran cantidad de huesos y se pudieron apreciar las paredes de la tumba (Figura 16). Entre los restos óseos se distinguieron durante la exploracion 5 cráneos en muy mal estado de conservación, vértebras, costillas, huesos largos, falangues, etcétera. Se trata de un osario y se confirma una vez más la costumbre de enterrar a los muertos debajo y en el centro de las viviendas.

\section{Estructura 30}

Esta es una plataforma rectangular que se localiza al oriente de la calle principal y se encontró su escalera de acceso muy bien conservada, con 4 peldaños y alfarda.

El material asociado es cerámica burda, caracoles, conchas, huesos de tortuga, fragmentos de navajas prismáticas y sflex.

Al realizar un pozo estratigráfico al centro de la estructura se localizó una hilada de piedra que formaba una caja o cista mortuoria, en su interior se localizaron restos humanos que no tenfan ninguna disposición anatomica. Tres de sus paredes estaban forradas con piedras muy bien trabajadas y tenían lajas o tapas; se obtuvieron 6 niveles artificiales, siendo el último de donde se recuperaron cráneos con deformación y mutilación dentaria muy destruidos y una falangue con un anillo de cobre. En términos generales el material oseo fue escaso (Figura 17).

\section{Entierros}

Estructura $25 B$

Es una pequeña plataforma que se encuentra en el lado norte, en donde se hizo una cala para limpiar el muro. Durante el trabajo de limpieza se encontró un entierro decúbito dorsal, es uno secundario, adulto y posiblemente de sexo masculino. Su orientación fue 


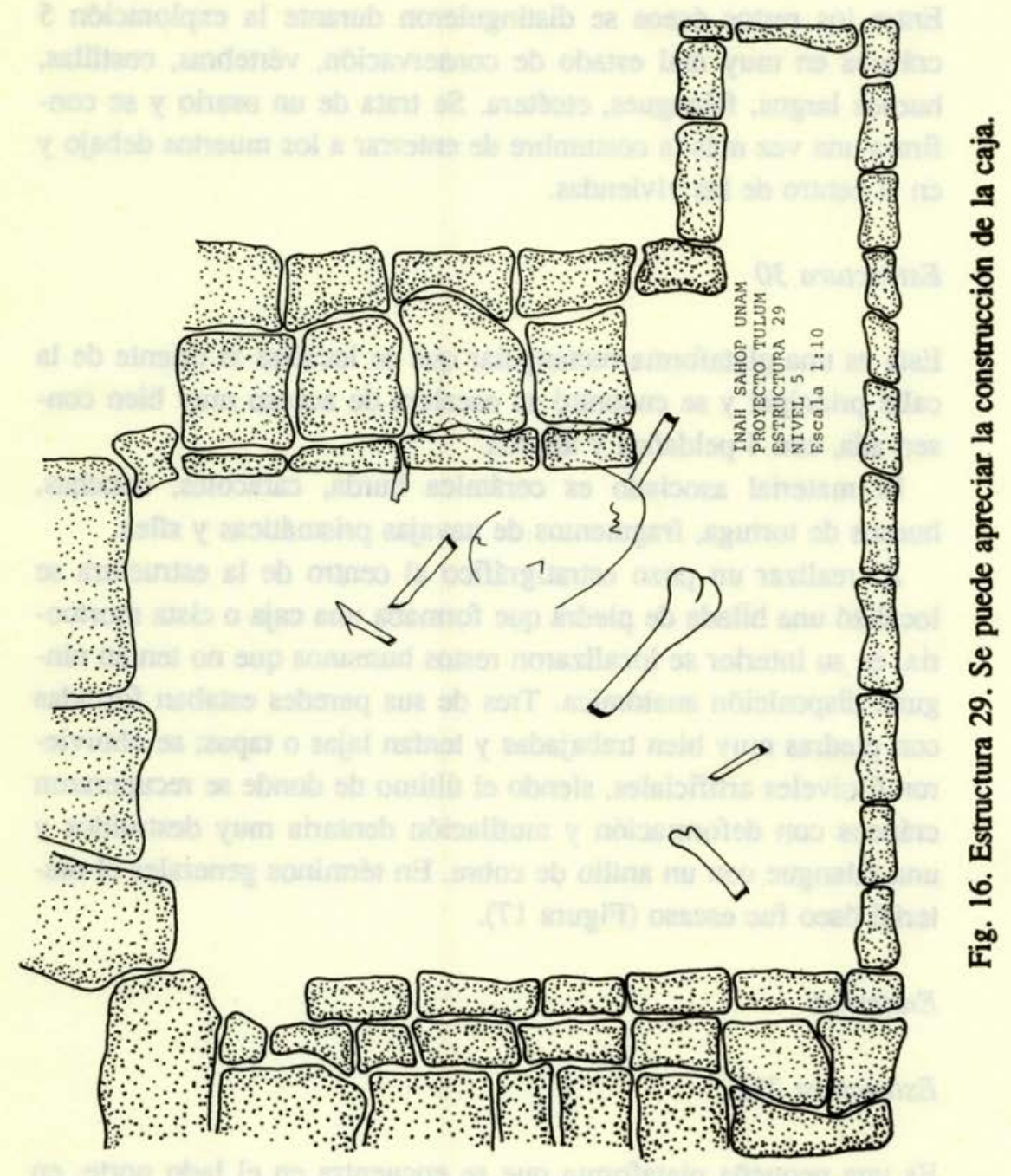




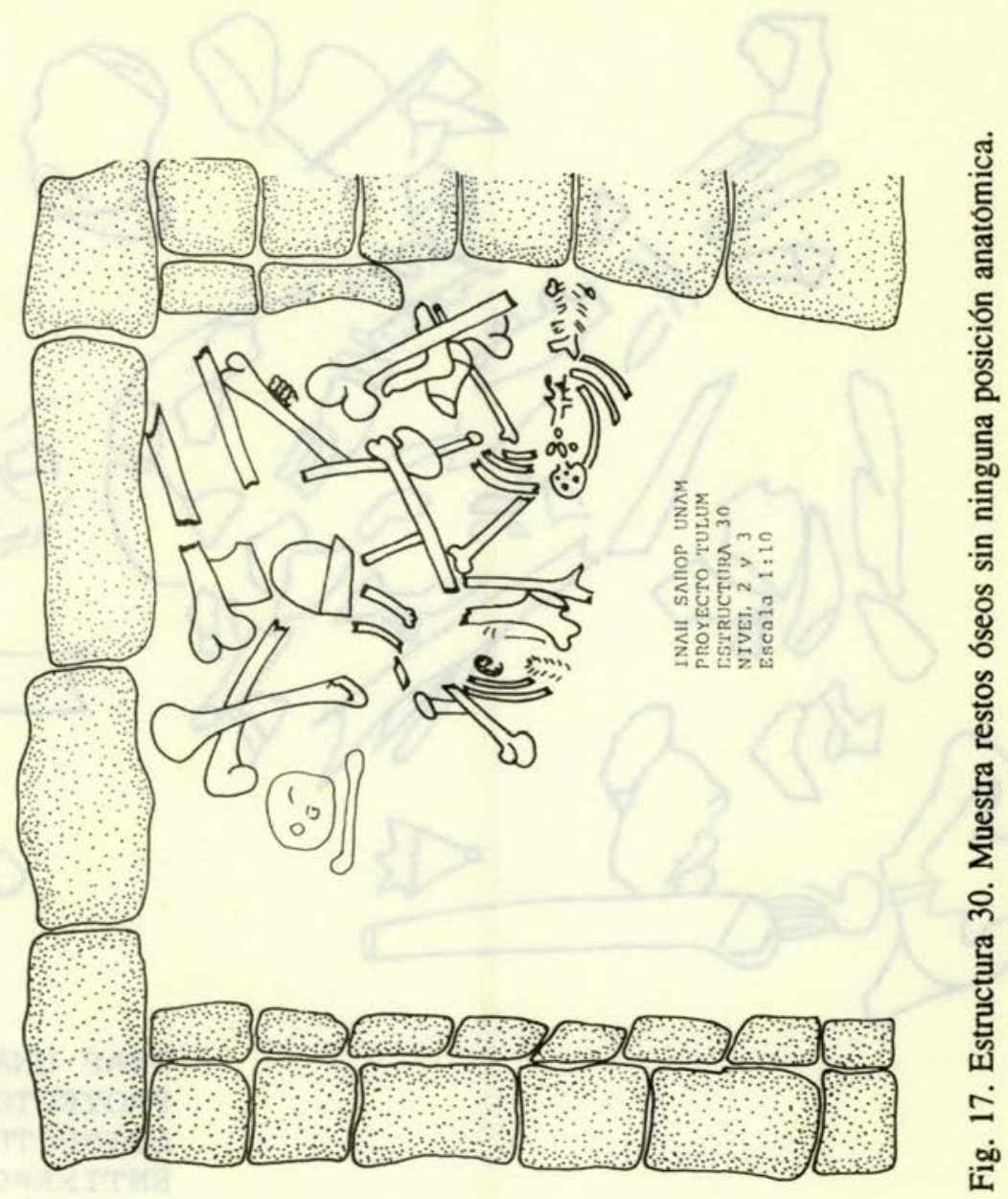




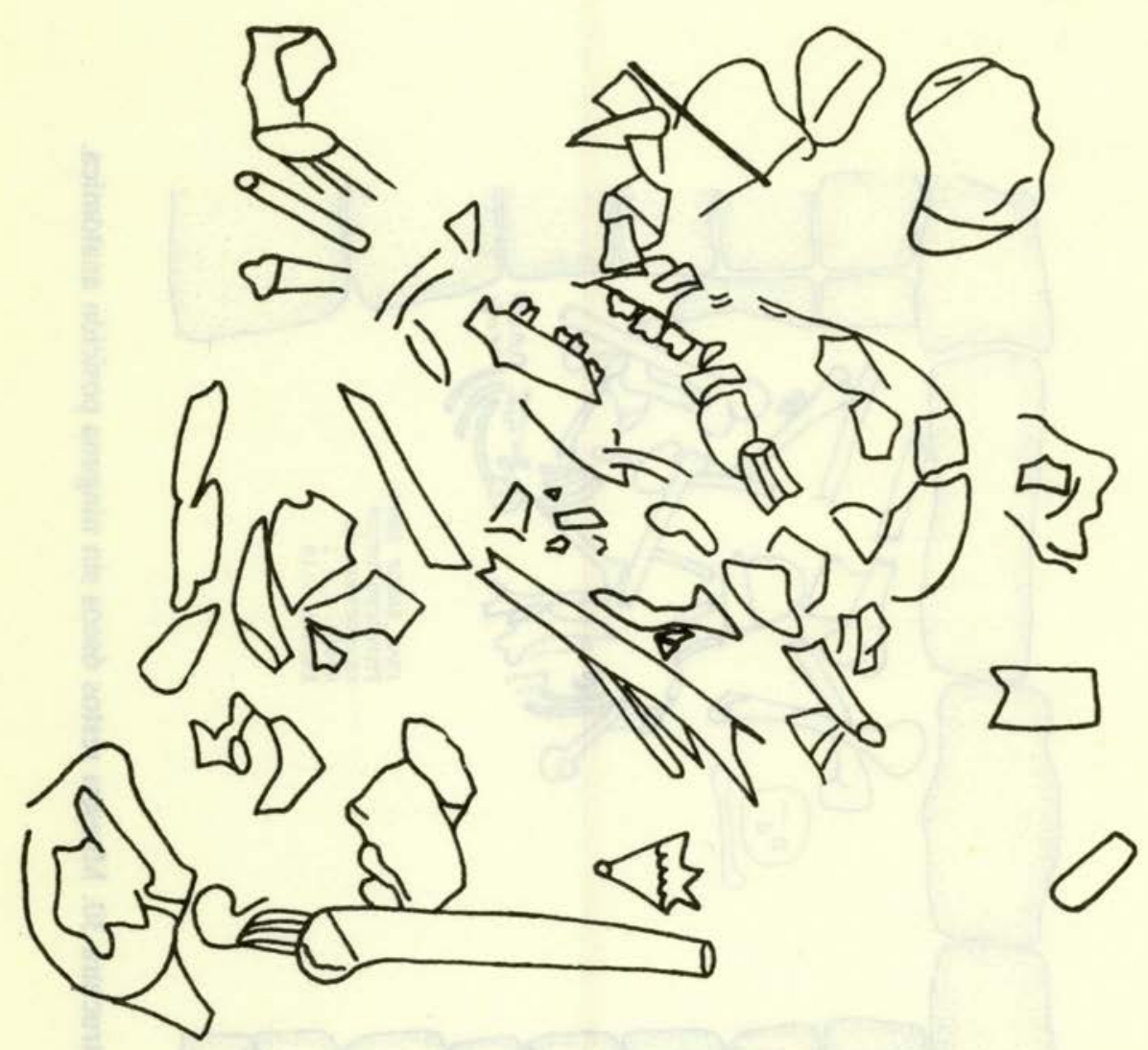

INAE UNAM SAHOP PROYECTO TULUM ESTRUCTURA 25 "B" ENTIERRO 1 ESCALA, $1: 20$

Fig. 18. Estructura 25b, es un entierro secundario de cúbito dorsal, Estudios de adulto. Maya. Vol. XIX, 1992 
de norte a sur y el estado de conservación no fue bueno. A pesar de que se le aplicó primal no se logró rescatar gran número de huesos completos. El material asociado fue caracol, cerámica y obsidiana (Figura 18).

\section{Estructura 27}

En ésta se hizo un pozo en que se exploraron seis capas y llegó a una oportunidad de $0.90 \mathrm{~cm}$ hasta la laja. El material asociado fue caracol, concha y cerámica. El entierro tenía la posición sedente con el cuerpo doblado hacia el este, con la columna vertebral rota; la cabeza se encontró entre las piernas viendo al oeste; abajo de la cabeza se hallo la cuenta de jade que se les ponía en la boca al morir. En la mano derecha se encontraron en las falanges 2 anillos de cobre. En la mano izquierda se encontraron 4 anillos, 2 en las falanges y 2 fuera de ellas, pero en las falanges quedo marcado por el cobre el lugar de los anillos. El individuo tenía deformación craneana del tipo lobular y dientes mutilados en forma de pico; no tenía ninguna muela.

\section{Estructura $34 B$}

Esta estructura está cerca de la Casa del Cenote y de la muralla; su forma es rectangular y de poca altura; alli se exploraron dos entierros, ambos primarios, uno con posición de decúbito dorsal flexionado y sexo masculino; el otro estaba en posición sedente y era de sexo masculino, en ambos casos con orientación hacia el poniente. Los entierros se encontraron en el interior de la plataforma y por debajo del piso, a una profundidad promedio de $0.80 \mathrm{~m}$ (Figura 19).

Entre los objetos asociados se tiene obsidiana, huesos de animal, canicas de barro, objetos de concha y cerámica. 


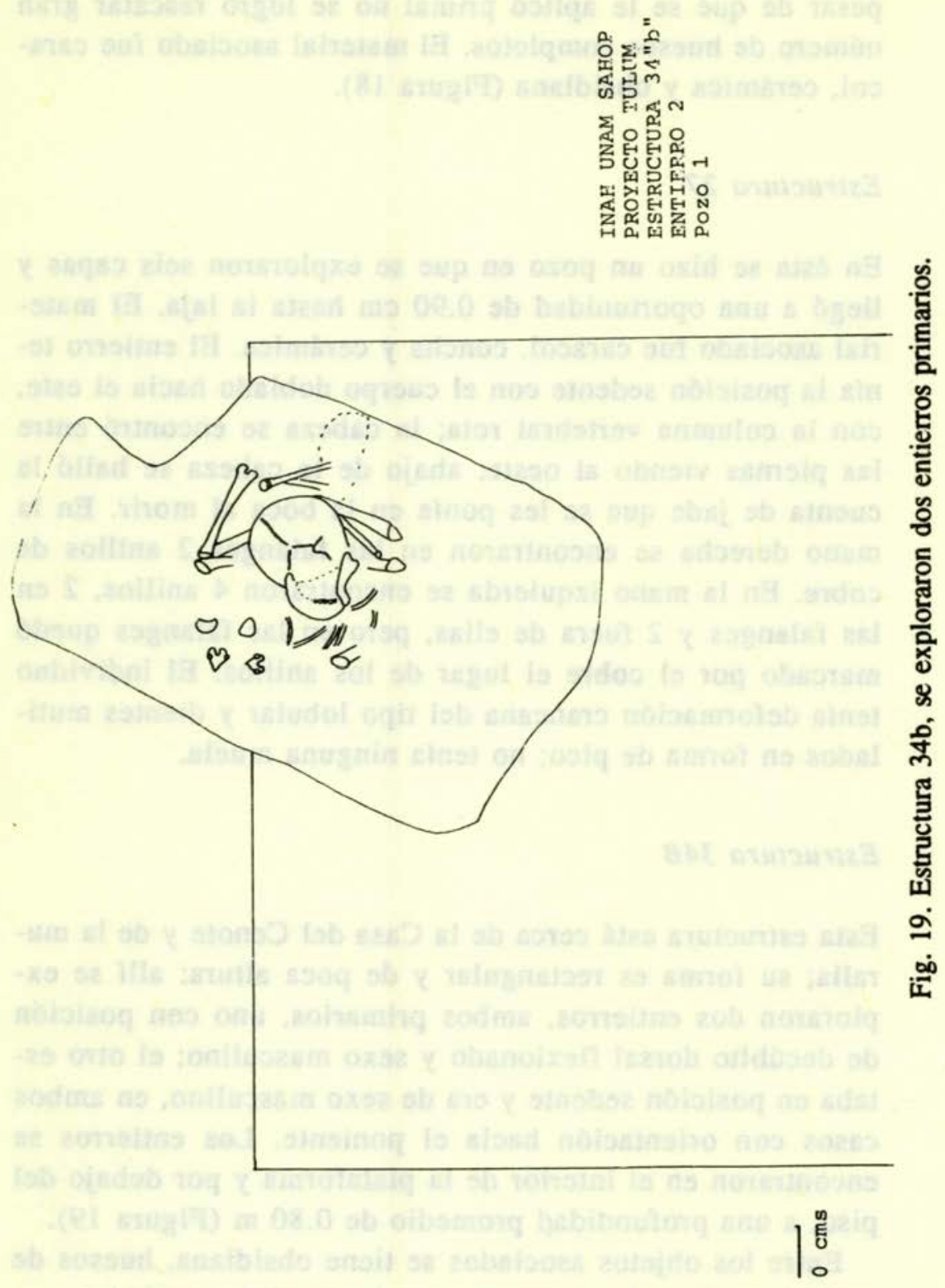

Estudios de Cultura Maya. Vol. XIX, 1992

Instituto de Investigaciones Filológicas/

Centro de Estudios Mayas, UNAM

ISSN 0185-2574 


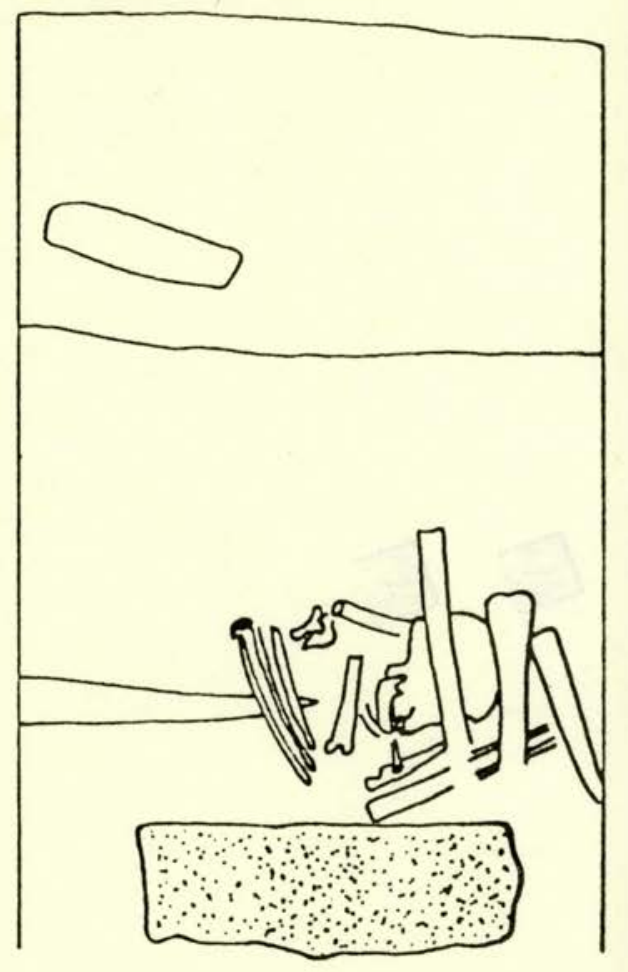

$10 \mathrm{cms}$.

INAH UNAM SAHOP PROYECTO TUI,UM ESTRUCTURA 4 r." "a" CUADRO 6 Pared Sur ESCP.LA $1: 10$

Fig. 20. Estructura 45a, enterramiento primario y directo. 

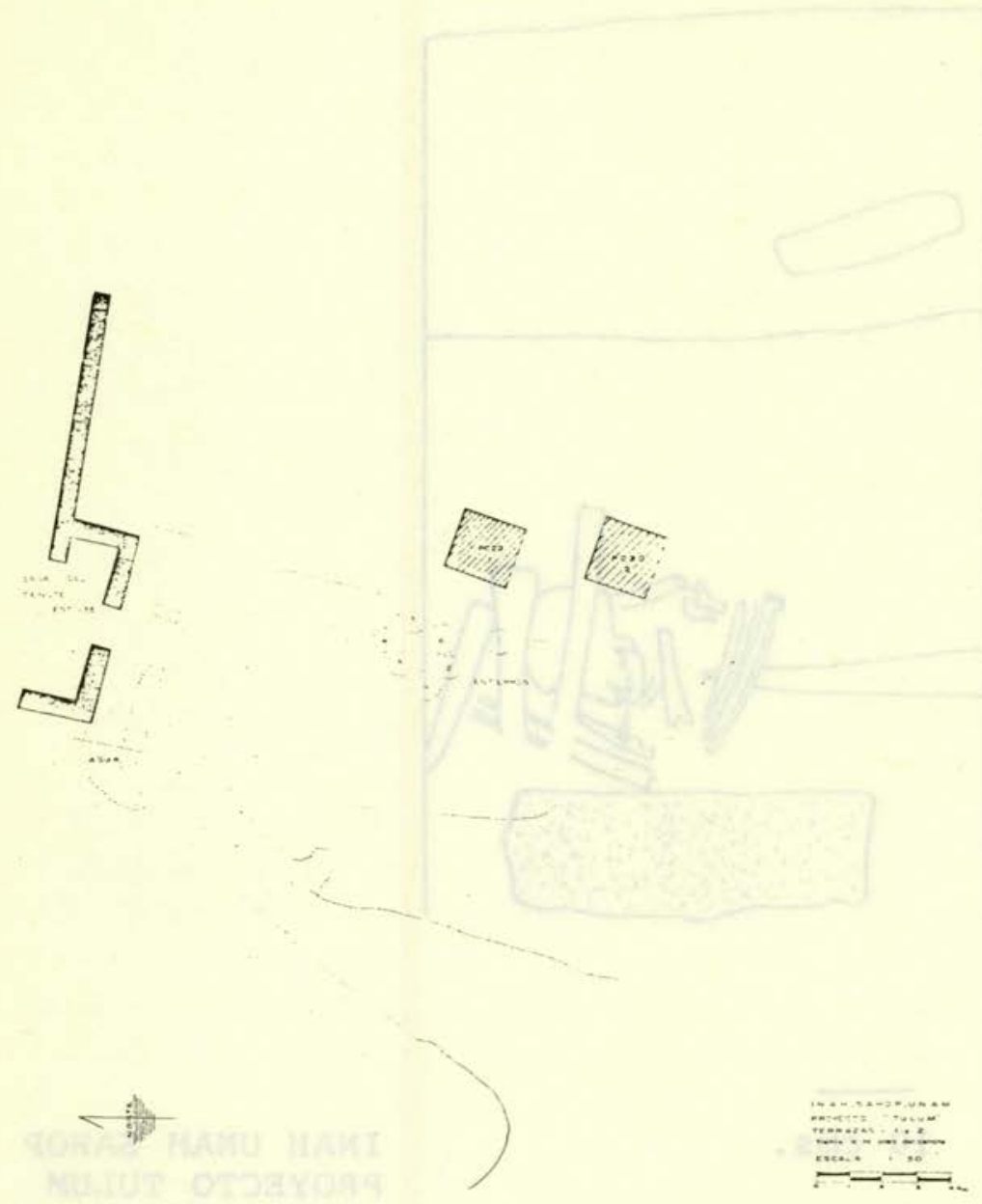

Fig. 21. Terrazas. Aquí se localizaron siete entierros, al mayoría de Estudios de ellos primarios. XIX, 1992

Instituto de Investigaciones Filológicas/

Centro de Estudios Mayas, UNAM

ISSN 0185-2574

http://www iifilologicas, unam.mx/estculmaya/ 
Esta es una plataforma que habfa sido excavada en 1974 por la arqueóloga Lourdes Martínez, y deja al descubierto las escaleras que dan acceso a la parte superior por el lado oeste; su forma es rectangular con alfardas y muros de talud y comisa.

En el interior se hizo una cala de $6 \mathrm{~m}$ por $2 \mathrm{~m}$, orientada de este a oeste, en los cuadros IV y V se encontraron 2 de los enterramientos, uno arriba del otro. Ambos eran primarios y directos; el primero con posición sedente y el segundo en decúbito lateral izquierdo. En términos generales el estado de conservación 'fue bueno, aunque en el campo se notó que tenfan deformación craneana. Su asociación fue con huesos de animal, concha, caracol y fragmentos de cerámica (Figura 20).

\section{Terrazas}

Al sur de la estructura 35 y frente a las estructuras 37 y 38 se exploraron 3 terrazas; en 2 de ellas se localizaron 7 entierros (Figura 21).

El primero fue directo, primario y en posición sedente. El entiero fue depositado en una fosa; la matriz en donde se encontro era de tierra fina con piedras y a una profundidad de $0.95 \mathrm{~m}$. El material asociado fue cerámica, huesos de animales, concha y caracol.

El entierro dos se encontro en muy mal estado de conservación y depositado en una fosa que contenía tierra fina y piedras grandes.

El entierro tres fue primario, en mal estado de conservación y representado por costillas y algunos huesos largos. Posiblemente tuvo una posición sedente. El material asociado fue cerámica, concha y huesos de animales.

El entierro cuatro era primario; se encontro sobre una matriz de tierra fina y por abajo de una concentración muy grande de cerámica. Los huesos encontrados estaban en mal estado de conservación, sólo se rescataron los huesos largos y no se pudo determinar 


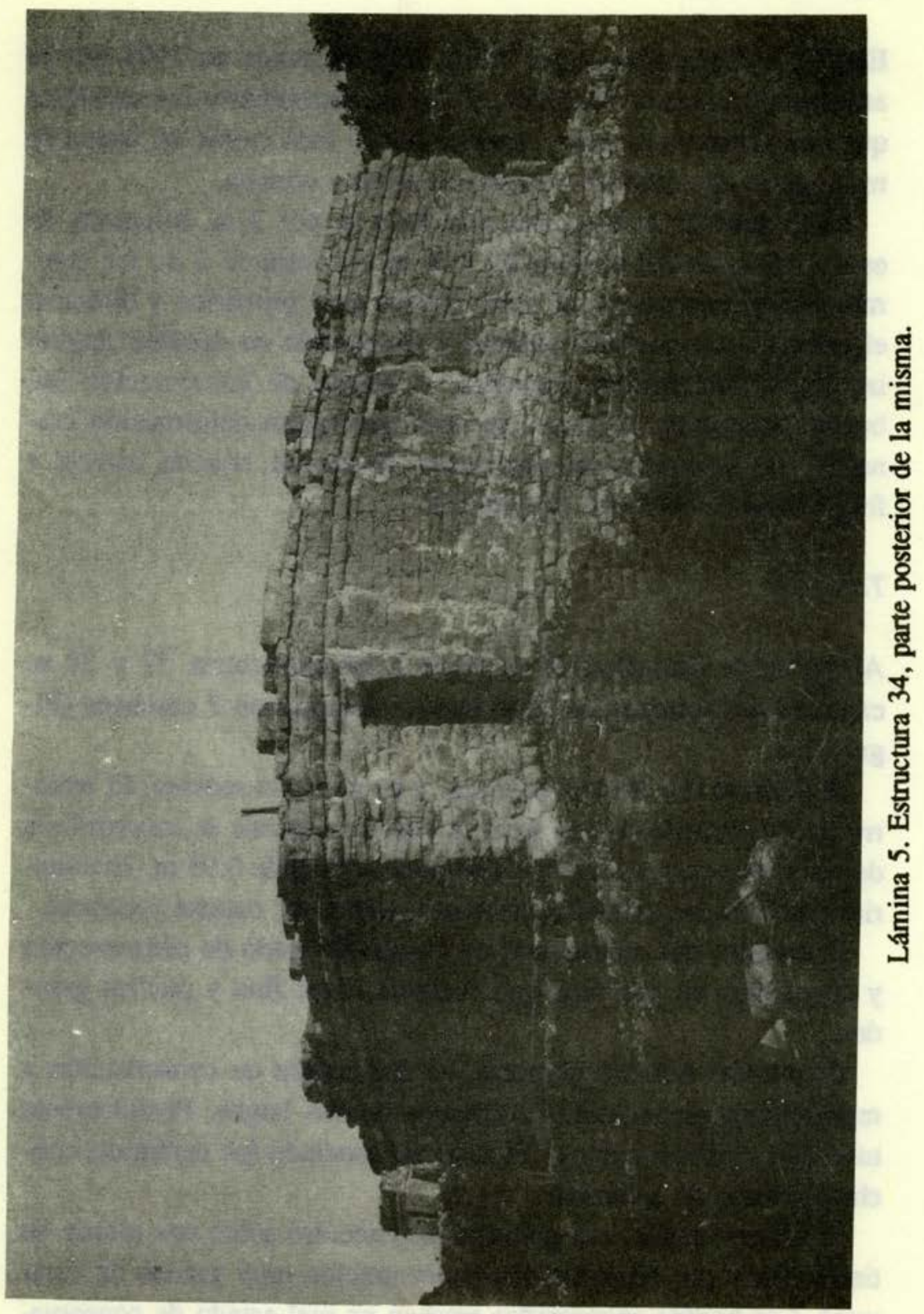

Estudios de Cultura Maya. Vol. XIX, 1992 Instituto de Investigaciones Filológicas/ Centro de Estudios Mayas, UNAM ISSN 0185-2574 


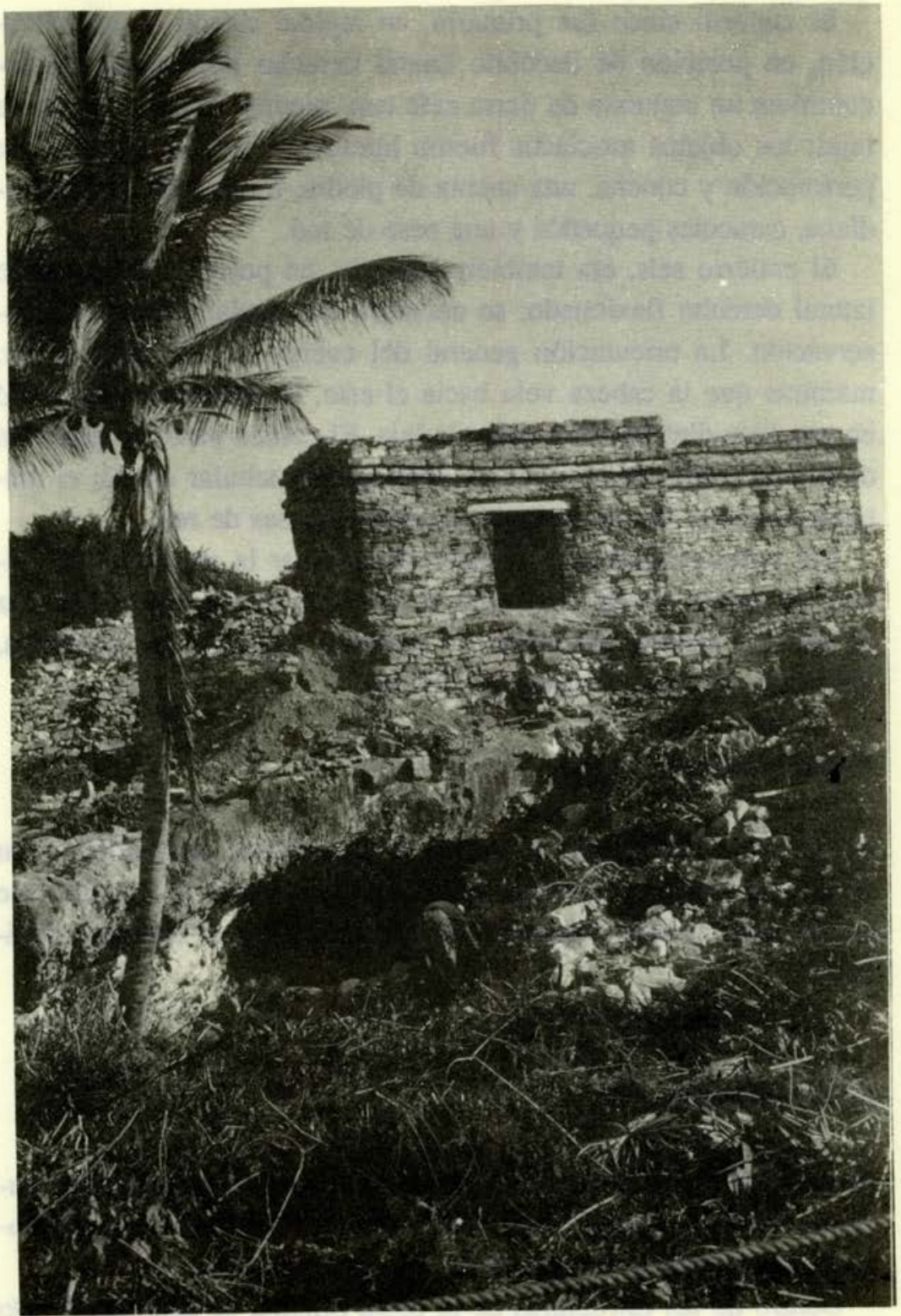

Lámina 6. Estructura 35 o La casa del cenote, vista general.

Estudios de Cultura Maya. Vol. XIX, 1992

Instituto de Investigaciones Filológicas/

Centro de Estudios Mayas, UNAM

ISSN 0185-2574 
la posición del entierro. Los objetos asociados fueron cerámica y huesos de animal.

El entierro cinco fue primario, en regular estado de conservación, en posición de decúbito lateral derecho flexionado. Se encontró en un contexto de tierra café con piedras sobre un lecho de lajas; los objetos asociados fueron huesos de animal, caracol con perforación y concha, una cuenta de piedra, 6 fragmentos de obsidiana, caracoles pequeños y una pesa de red.

El entierro seis, era también primario, en posición de decúbito lateral derecho flexionado; se encontró en regular estado de conservación. La orientación general del cuerpo fue de norte a sur, mientras que la cabeza veía hacia el este. El entierro se encontró en una fosa directamente sobre la laja. El cráneo yacía en posición de norma lateral derecha y con deformación tabular erecta; el material asociado fue de cerámica, concha y pesas de red.

Del entierro siete sólo se pudo determinar la posición del cráneo, de norma lateral izquierda; se localizo en una fosa de matriz de tierra y piedras pequeñas. El material asociado fue cerámica, obsidiana, concha y huesos de animal.

\section{Recinto interior}

No se pudo determinar su forma ni la relación anatómica, y su estado de conservación era malo. Aparentemente el entierro fue hecho sobre la laja. Como objeto asociado sólo se encontró cerámica.

\section{Comentario final}

En este trabajo se pueden ver las diferencias que existen entre Tulum y los demás sitios de la costa oriental. También se puede notar la singularidad de algunos de sus enterramientos.

Dentro de las estructuras de la costa oriental se han encontrado cistas, tumbas y gran cantidad de enterramientos individuales, 
comparables con el resto de la zona maya y Mesoamérica en general. Tal vez lo interesante y digno de resaltar en este trabajo son algunas de las peculiaridades que se dan en la costa oriental y en Tulum específicamente, que se encuentran localizadas en el eje central de la estructura y todas posiblemente sean osarios que se encuentran recubiertos de estuco y con formas variadas: cruciformes, cuadradas y rectangulares.

En Can Cun se encontró un número considerable de enterramientos primarios directos al interior de las plataformas, pero con la característica de que se excavaban orificios redondos.

Los serranos de la región del Usumacinta enterraban a los muertos flexionados, en posición sedente, dentro de un hoyo redondo abierto en la tierra, con comida para él y para los animales de que se alimetaban en vida, para que éstos no les hicieran daño en el otro mundo, y en particular para que los perros que hubieran matado y comido no los mordieran. (Lopez de Cogolludo 1955, lib. XII, cap. VII, p. 347). Esta información de López de Cogolludo no deja de ser interesante ya que diferentes investigadores han hablado con cierta insistencia de la posibilidad de que en la costa oriental exista ocupación de chontales, y éste puede ser un dato más que venga a ayudar a esclarecer este tipo de contactos.

En cuanto a los materiales que se encuentran en estas tumbas, existe la posibilidad de que las estatuas huecas de barro, también citadas por Landa, puedan ser vasijas antropomorfas (frecuentemente designadas como braseros, pero que lo mismo pudieran ser urnas) como las que conocemos de Mayapán y los sitios de la costa del Caribe, contemporáneas de la segunda parte del Posclásico, es decir de los siglosxiII y xvi (Ruz L. 1968:178).

Tal vez lo más importante de las tumbas que se exploraron en Tulum sean los osarios, y entre ellos los que se encontraron en las estructuras 34 y 35 en donde se localizaron miles de fragmentos de huesos que fueron registrados durante la exploración; desde el campo pudimos apreciar la abundancia de huesos largos, costillas y vértebras y la falta de cráneos en la tumba de la estructura 34 o Casa del Cenote, lo que nos indicaba, en un primer momento, 
cierta peculiaridad de la misma; después también se notó el modo de depositarlos en su interior y, por medio de las pesas de red se pudo inferir que fueron introducidos con redes. Es decir que debíamos de buscar una explicación del sistema de enterramientos de Tulum y, gracias a las fuentes históricas, creemos que podemos acercarnos a tal interpretación.

En otras fiestas mensuales, los huesos de los prisioneros sacrificados juegan un papel importante. Es así que en el segundo mes, Tlacaxipethualiztli, en honor del dios Xipe Totec, después de los sacrificios y desollamiento de las víctimas, el dueño del cautivo, cuya carne había comido, y componíale con papeles, y con una soga la colgaba de aquel madero que había hincado en el patio (Sahagún 1956 lib. II, cap. XXII:145.)

Esta podría ser una explicación de por qué se encuentran determinados tipos de huesos en esas tumbas, por la costumbre de los sacrificios humanos y por lo que dice Landa (1978:59) de que quemaban ciertas partes de su cuerpo y enterraban los residuos como tenían de costumbre.

Otro hecho de interés que pudimos observar en la tumba de la estructura 35 fue el encontrar 13 cráneos sin la mandíbula inferior; desde el hallazgo mismo nos llamó poderosamente la atención ese hecho, el cual debería tener alguna explicación y nos tuvimos que concentrar en la búsqueda de una explicación, y creemos haberla hallado en las fuentes históricas y en la etnografía.

Landa refiere la costumbre de quitar la quijada de los caídos en el combate para usarla en el brazo, como un amuleto que conservaba el valor del guerrero muerto. Los lacandones guardan junto con sus ídolos de barro, las mandíbulas de algunos animales como el venado, el mono y el jabalí, seguramente con propósitos mágicos (Sapper 1891:893; Tozzer 1907:115).

En la tumba siete de Monte Albán, trabajada por Caso A., también se cita el hallazgo de mandíbulas, lo mismo que en uno de los objetos de oro hallados en la tumba se representa a un personaje con la mandíbula humana sobrepuesta; es decir que esta cos- 
tumbre debió de estar muy difundida en toda Mesoamérica. Aquí simplemente señalamos ese hecho que no deja de ser interesante.

Los osarios al parecer son comunes en la costa oriental, ya que están reportados para Cozumel y uno para Playa del Carmen. También se infiere por los datos de A. Romano que ésa era una costumbre común en la zona maya. En Tulum se excavaron, al centro de las estructuras, tumbas que eran osarios y, por las exploraciones realizadas, nos atrevemos a decir que la mayoría de las plataformas tiene la tumba-osario al centro.

Posiblemente una de las inferencias más interesantes que hemos hecho por medio de las tumbas es la de que pertenecieran a un linaje. Ya con anterioridad habíamos dicho que por la distribución de las estructuras y el comportamiento que existía con la zona habitacional del sitio se podía pensar que estas estructuras eran cívico religiosas y que su función bien pudo estar relacionada con grupos de parentesco. Ahora pensamos más firmemente que estas tumbas tenían una función familiar, y que seguramente allí se depositaban los restos óseos de los mismos en diferentes tiempos, conservándose así una tradición familiar; en el reporte de los restos óseos se dice que existen restos de mujeres, niños y adultos.

Con esto s6lo pretendemos plantear la posibilidad de inferir que estos osarios fueron tumbas familiares y no pretendemos desechar la posibilidad de pensar que tuvieran la función de enterrar a guerreros muertos en batalla y/o prisioneros importantes.

Reconocimientos: En la exploración de las tumbas y entierros participaron Martha Villalta (tumba de la estructura 35), Aurora Leiva (tumba de la estructura 20), Peter Smith, Antonio Benavides, Teresa Miranda, Sara Novelo; estudiantes de la Universidad de Veracruz y algunos de los trabajadores del Proyecto. Gracias a su labor se puede presentar este trabajo. 


\section{BIBLIOGRAFIA}

ANDRews P. ANTonio y Fernando Robles (Coords.)

1986 Excavaciones arqueológicas en El Meco, Quintana Roo, 1977. Colección cientifica. Serie Arqueología, INAH, México.

BINFORD, L.

1971 "Mortuary Practices: Their Study and Potential", Approaches to the Social Dimensions of Morttuary Practices. J. A. Brown (ed.) Memoirs of the Society for American Archaeology no. 25.

Brown, J. A.

1981 "The Search for Rank in Prehistoric Burial", The Archaeology of Death, R. Chapman; I. Kinnes y R. Randsborg (eds.), Cambridge University Press.

Caso, Alfonso

1969 El Tesoro de Monte Albán, INAH, SEP, México

COMAS, JuAN

1966 "Características físicas de la familia lingüística maya". Serie Antropológica 20. Instituto de Investigaciones Históricas, UNAM, México.

Fernández, Miguel Ángel.

1945 "Las ruinas de Tulum I", Anales del Museo Nacional de Arqueología, Historia y Etnografia, Tomo 3, p. 109-115, M. N., México.

LANDA, DIEGo DE

1978 Relación de las cosas de Yucatán, 9a. ed., introd. Ángel María Garibay, Porrúa, México.

LOPEZ DE COGOLLUDO, FRAY DIEGO

1955 Historia de Yucatán. Tres tomos. Comisión de Historia Campeche, Campeche, México.

LOTHROP, SAMUEl K.

1924 Tulum, an Archaeological Study of the East Coast of Yucatan, Carnegie Institution of Washington, Pub. 335, Washington, D.C.

MÁRQuez, Lourdes (Coord.).

1982 "Playa del Carmen. Una población de la costa oriental en el Postclásico. (Un estudio osteológico.)" Colección cientifica 119. Antropología Física. C.R.S. INAH. México.

MiLLeR A.F. y NaNCY FarRISS

1985 "Sincretismo religioso en el Yucatán colonial: La eviden- 
cia arqueológica y etnohistórica de Tancah", Revista Mexicana de Estudios Antropológicos. Tomo XXXI, pp. 81100. Sociedad de Antropología, México.

Ramos, Rosa Ma.

1978 "Algunas observaciones sobre los enterramientos humanos en el sitio "El Rey" (Can Cun)", Anales de Antropología. Vol. XV, pp. 251-266. Instituto de Investigaciones Antro-

Romano, Arturo pológicas, UNAM, México.

1974 "Sistemas de enterramientos". Antropología Fisica, época prehispánica. México panorama histórico y cultural ,3:81112, INAH, México.

Ruz L., ALBERTO

1968 Costumbres funerarias de los antiguos mayas. Seminario de Cultura Maya, UNAM. México.

Santiluan S., Patricia

1986 La Casa habitación en Tulum, Quintana Roo. Tesis. ENAH. México.

SAHAGUN, FRAY BERNARDINO DE

1956 Historia general de las cosas de la Nueva España. numeración, anotaciones y apéndices de Ángel Ma. Garibay, 4 vols., México, Editorial Porrúa (Biblioteca Porrúa, 8-11).

SAPPER, $K$.

1901 "Speise und Trank der Kekchi-Indianer", Globus. 80:25424.

SAXE, A.A.

1971 "Social Dimensions of Mortuary Practices in a Mesolithic Population from Wadi Halfa: Sudan", Approaches to the Social Dimensions of Mortuary Practices, J. A. Brown et al. (eds.), Memoirs of the Society for American Archaeology No. 25.

Serra P. Mari Carmen y Yoko Sugtura

1988 "Las costumbres funerarias en dos momentos históricos en Mesoamérica: Formativo Medio y Formativo Terminal". Coloquio V. Gordon Childe, Linda Manzanilla (ed.). UNAM, México.

TOZZER, A. M.

1907 A comparative study of the Mayas and the Lacandones. New York. Mc Millan Co.

VILla RoJas, Alfonso

1985 Estudios Etnologicos. Los Mayas. Instituto de Investigaciones Antropológicas. UNAM, México. 


\section{VARGAS P., ERnESTO}

1985 Informe sobre los enterramientos en Tulum. Vol. III de Informes. Mecanuscrito, México. 

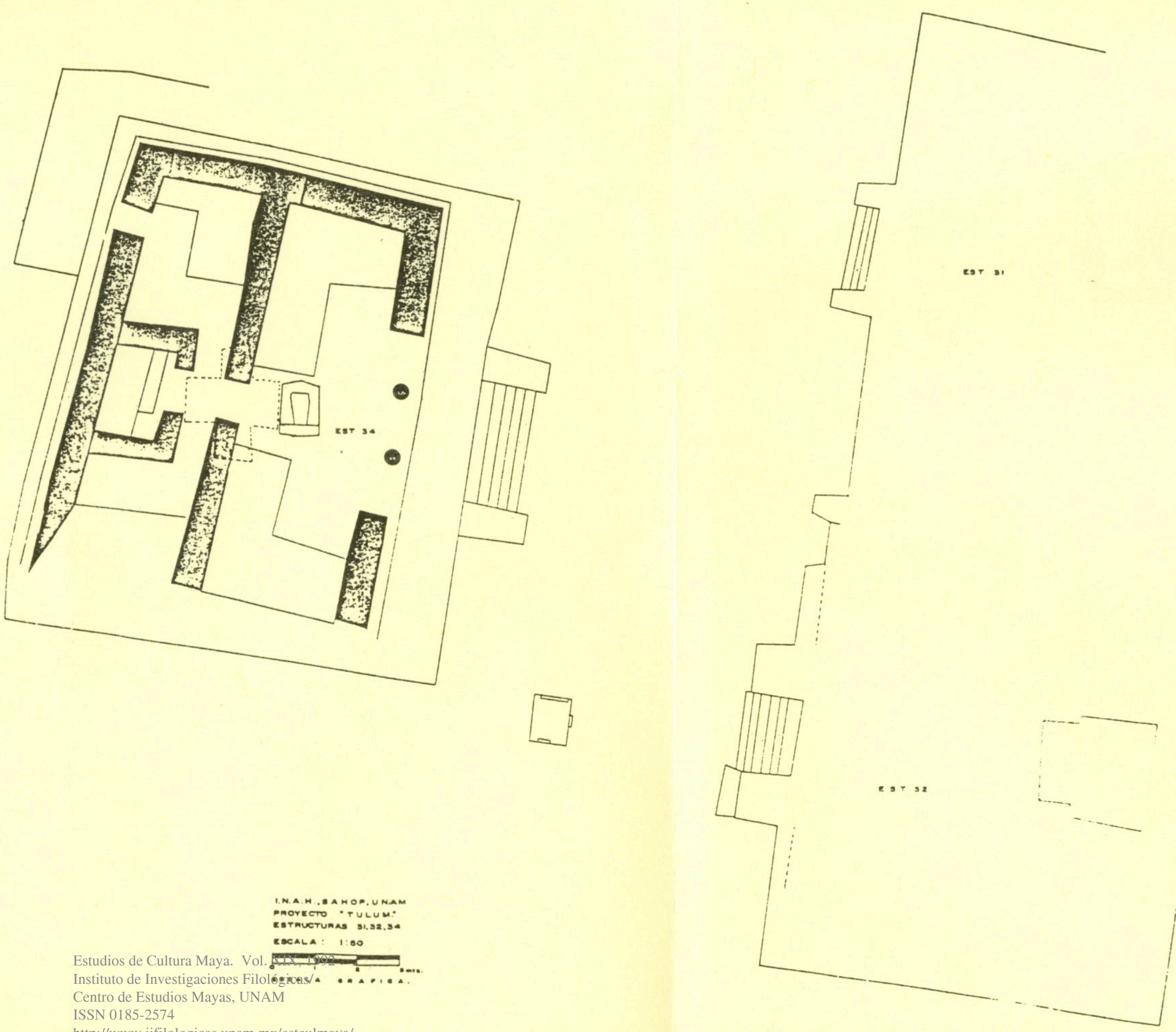

Estudios de Cultura Maya. Vol.

Instituto de Investigaciones Filológices/. . . . . . . .

Centro de Estudios Mayas, UNAM

ISSN 0185-2574

http://www iifilologicas unam mx/estculmaya/ 


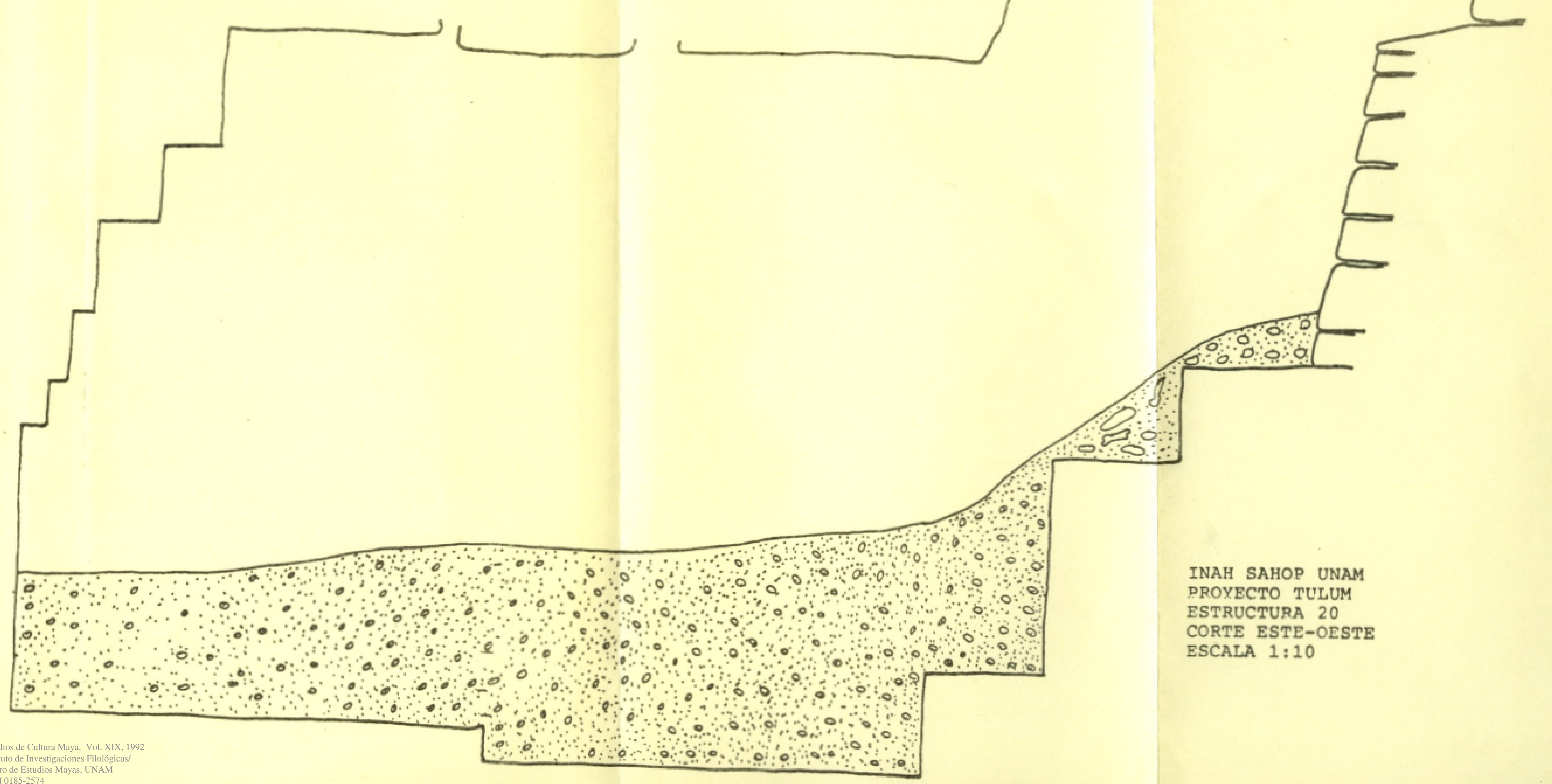




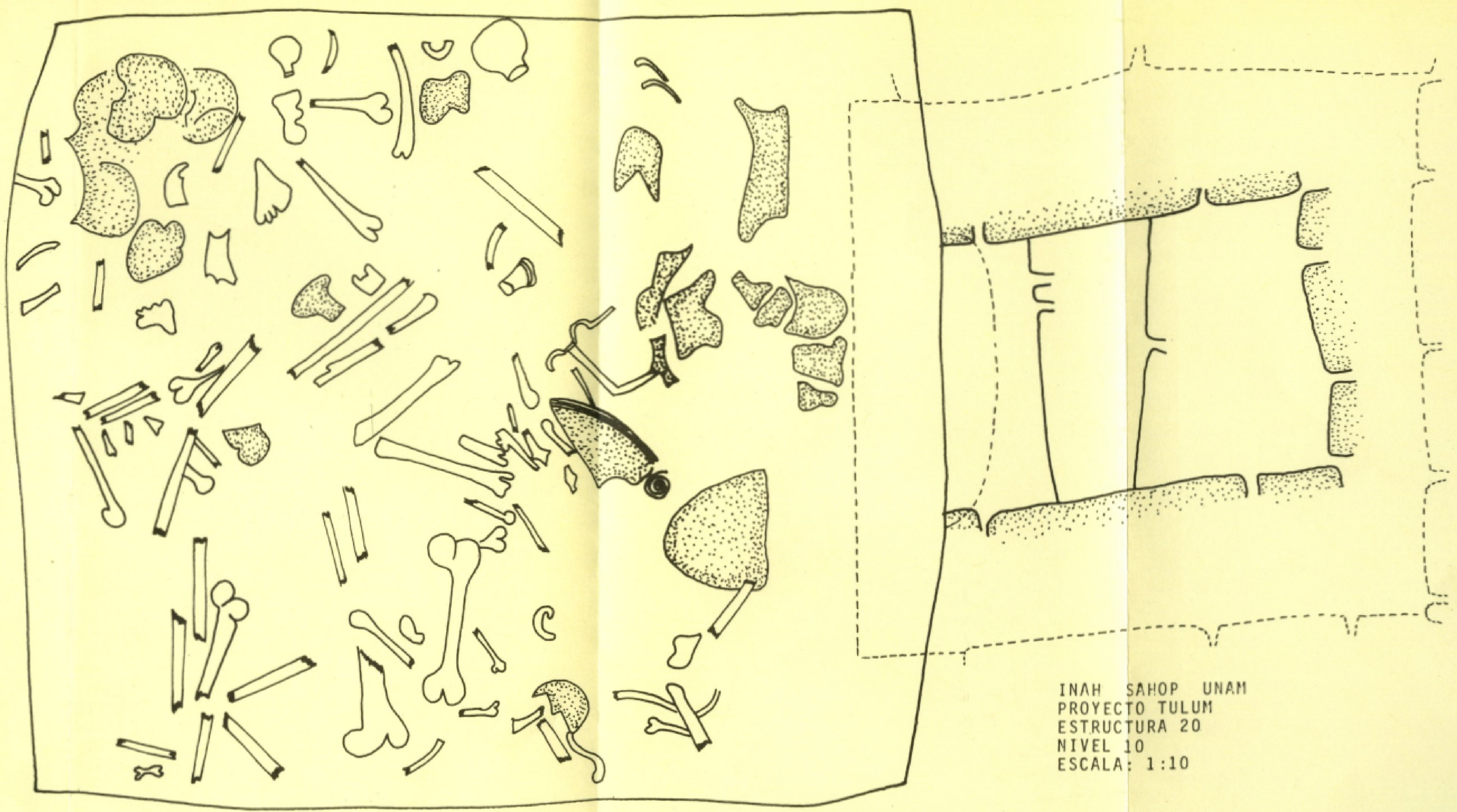




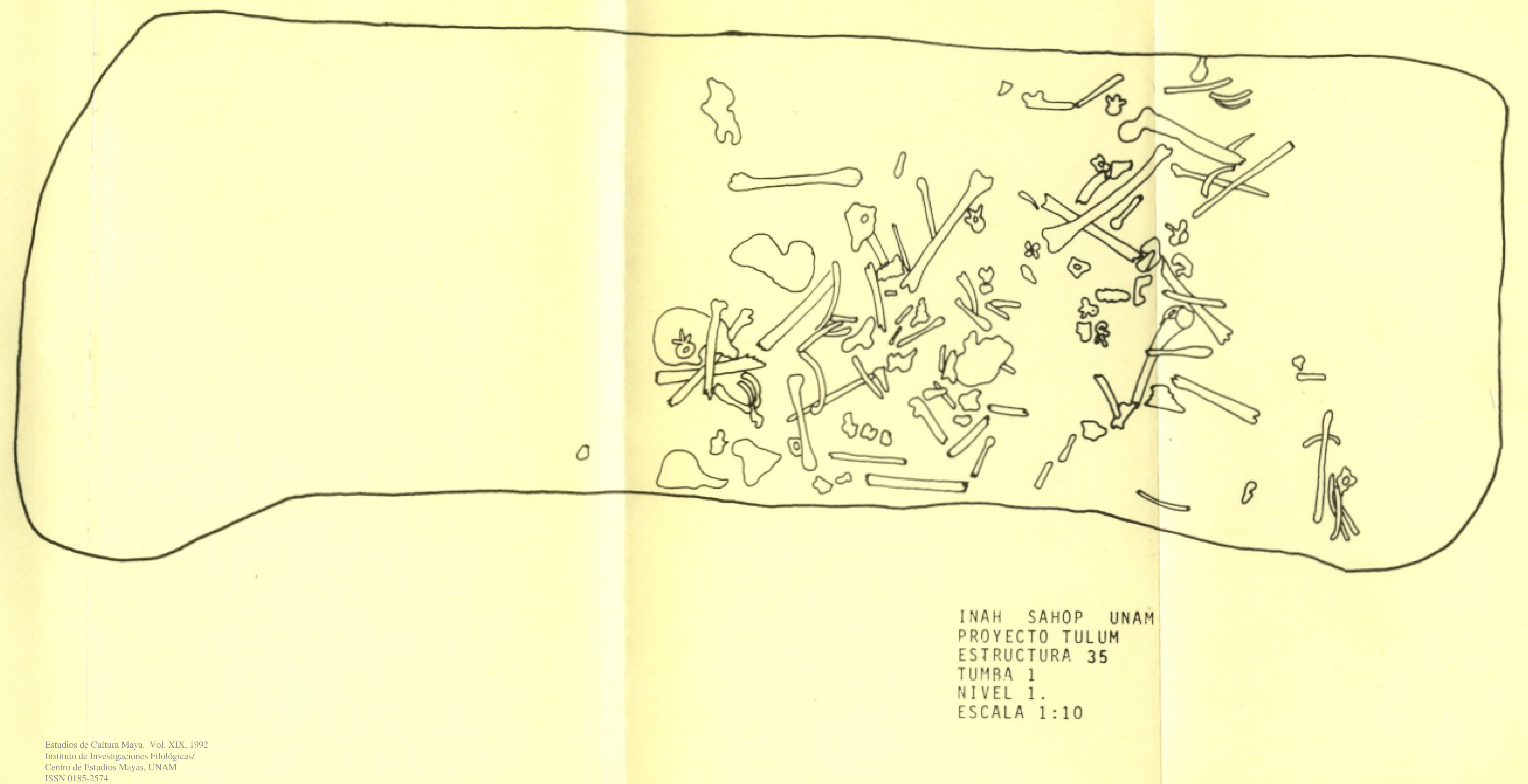




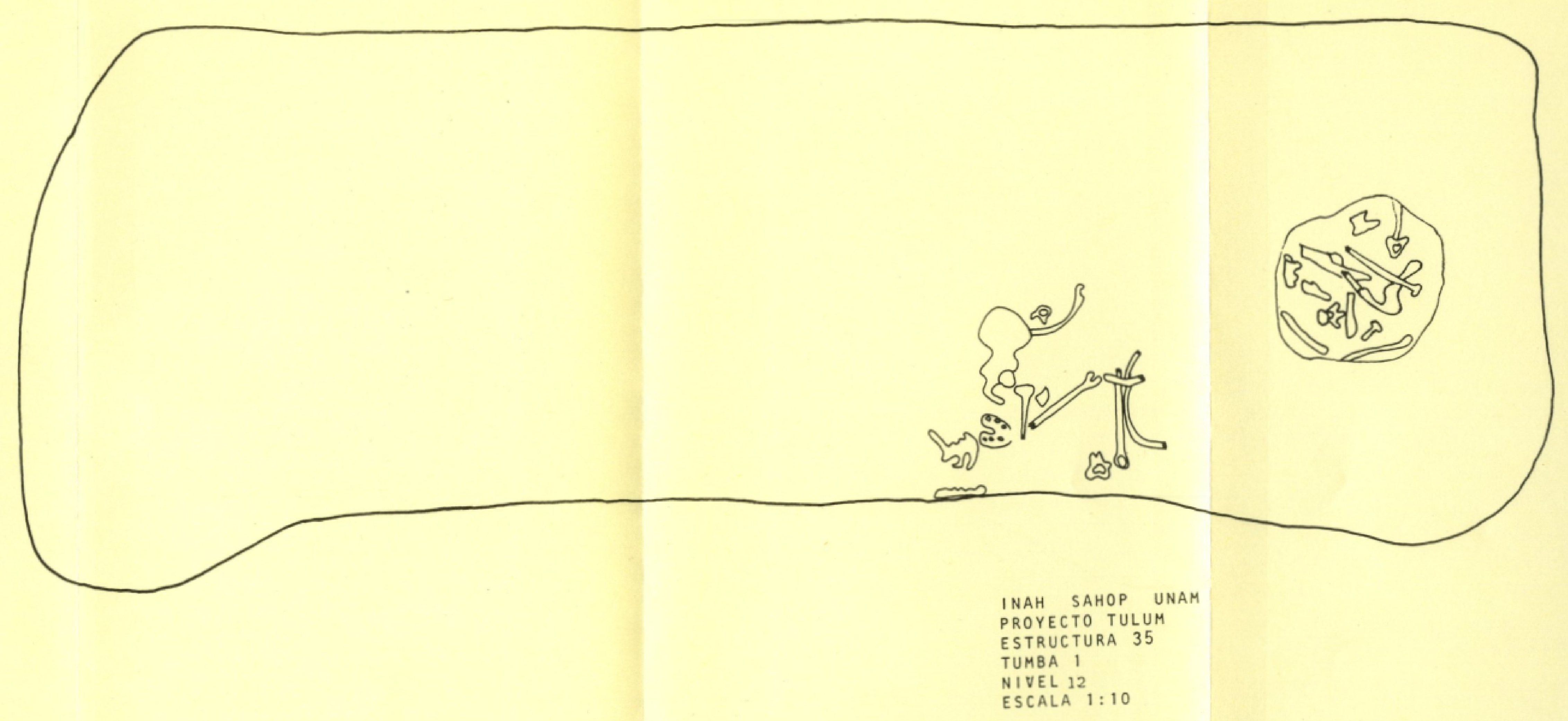




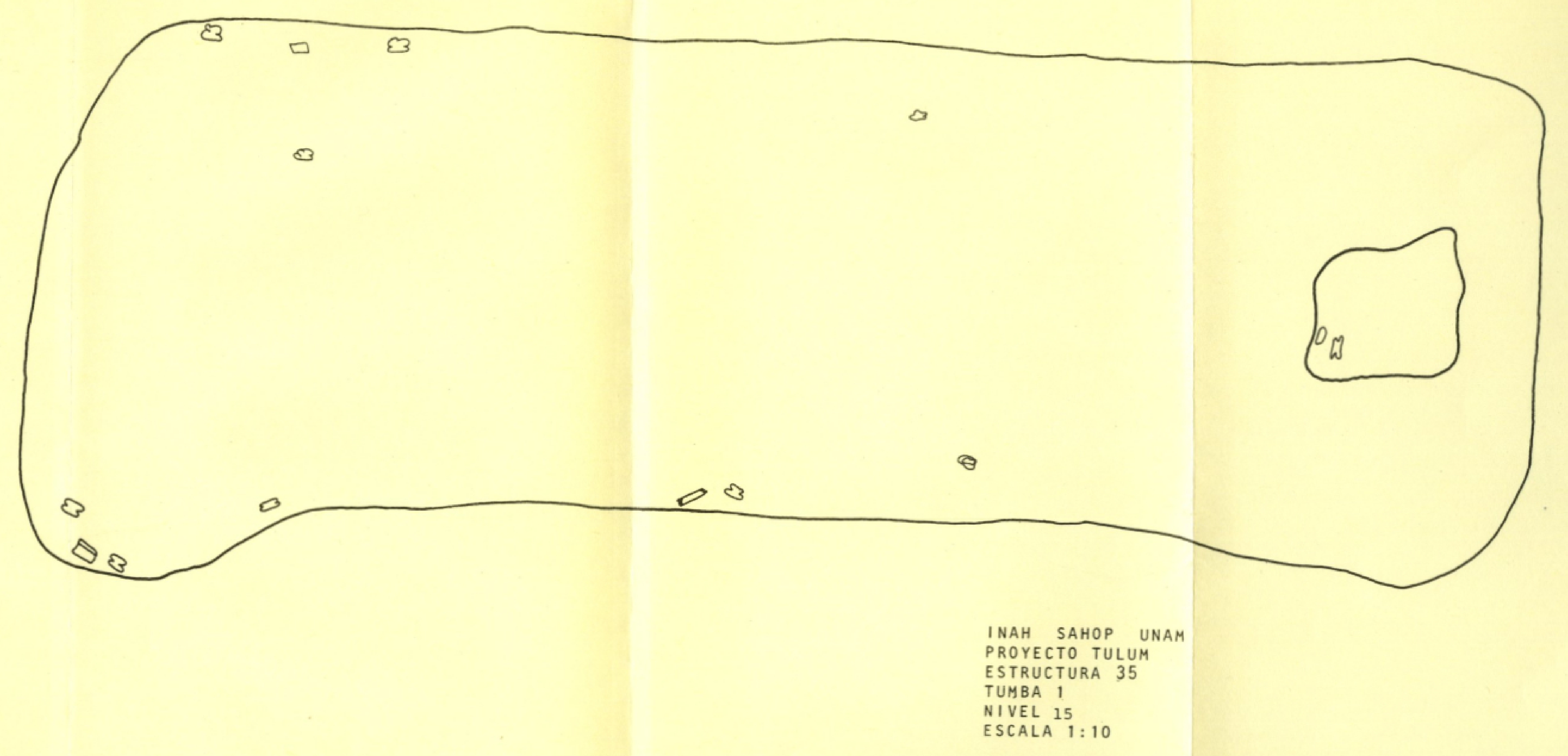

